\title{
Organizational Models in Athletic Training and the Effect on the Quality of Care Delivered
}

\author{
Matthew Ferreira \\ West Virginia University, mf0055@mix.wvu.edu
}

Follow this and additional works at: https://researchrepository.wvu.edu/etd

Part of the Sports Medicine Commons, and the Sports Sciences Commons

\section{Recommended Citation}

Ferreira, Matthew, "Organizational Models in Athletic Training and the Effect on the Quality of Care Delivered" (2019). Graduate Theses, Dissertations, and Problem Reports. 3849.

https://researchrepository.wvu.edu/etd/3849

This Thesis is protected by copyright and/or related rights. It has been brought to you by the The Research Repository @ WVU with permission from the rights-holder(s). You are free to use this Thesis in any way that is permitted by the copyright and related rights legislation that applies to your use. For other uses you must obtain permission from the rights-holder(s) directly, unless additional rights are indicated by a Creative Commons license in the record and/ or on the work itself. This Thesis has been accepted for inclusion in WVU Graduate Theses, Dissertations, and Problem Reports collection by an authorized administrator of The Research Repository @ WVU. For more information, please contact researchrepository@mail.wvu.edu. 
2019

Organizational Models in Athletic Training and the Effect on the Quality of Care Delivered

Matthew Ferreira

Follow this and additional works at: https://researchrepository.wvu.edu/etd

Part of the Sports Medicine Commons, and the Sports Sciences Commons 
Organizational Models in Athletic Training and the Effect on the Quality of Care Delivered

Matthew Ferreira, ATC, CSCS

Thesis Submitted to the College of Physical Activity and Sport Sciences

at West Virginia University

in partial fulfillment of the requirements for the degree of

Master of Science in

Athletic Training

Michelle A. Sandrey, PhD, ATC, Chair

Jean L. McCrory, PhD

Travis Randolph, PA-C, ATC

Department of Sport Sciences

Morgantown, West Virginia

2019

Key Words: Quality, Care, Coverage, Organizational Models, Athletic Training Copyright 2019 Matthew Ferreira 


\section{ABSTRACT \\ Organizational Models in Athletic Training and the Effect on the Quality of Care Delivered \\ Matthew Ferreira, ATC, CSCS}

Context: Quality of care is an ethical priority to all healthcare professionals. Healthcare fields such as nursing and physical therapy have made changes in staff size and focus that have increased the quality of care provided to patients. The athletic training field has not made changes to the organizational structure. Thus, the quality of care delivered by athletic trainers is an understudied topic. Likewise, the organizational models have just recently been explored in the literature. Objective: Identify differences in the three models of organization (academic, athletic, and medical) related to quality of care delivered and coverage versus care. Design: This study was a prospective exploratory questionnaire analysis. Setting: Clinically practicing athletic trainers in the NCAA Division I setting of the United States. Patients and Other Participants: A randomized list of 1,000 National Athletic Trainers' Association (NATA) members who are Board of Certification (BOC) certified and clinically practicing in the NCAA Division I setting. The list was used to recruit participants to the questionnaire. Participants were required to be full-time, clinically practicing athletic trainers in the NCAA Division I setting. Participants were excluded if they are less than 18 years of age, not practicing in the Division I setting as an athletic trainer (AT), and are not employed full time (i.e. GAs, interns, residents). There were 66 valid responses recorded of the 1,000 potential participants $(0.06 \%$ return rate). Intervention: Participants were contacted via the NATA Research Survey Service via e-mail. The e-mail contained a cover letter and link to a questionnaire. Two-weeks after the initial e-mail a followup letter with the link to the questionnaire was sent to encourage participation. The questionnaire contained 52-questions related to the perception of the quality of care delivered, whether the focus is on coverage or care, and demographic questions. Main Outcome Measures: Athletic trainers self-perception of the quality of healthcare they delivered and whether the focus is on coverage or care and the relationship to the model of organization (academic, athletic, medical) used. Results: $86.5 \%$ of participants were categorized into the athletics model of organization. There were 49 (74\%) of participants in the high-quality care category. Seventy-seven percent of participants were in the high-coverage category. There was a significant relationship $(\mathrm{p}=.021)$ between the model of organization and the quality of care category. Conclusion: Athletic trainer self-perception of the quality of care delivered to patient is high. Athletic trainers in the medical model provided the highest quality care, but they are also still spending time in the work day providing coverage to practices and competitions. The athletics model, though not the ideal environment for quality healthcare, could foster quality if the staff, facilities, and team physicians make improving the quality a priority. 


\title{
ACKNOWLEDGEMENTS
}

\author{
To My Family
}

Thank you for your constant love and support. You have always believed in me and my dreams. You have given me the world and I cannot begin to tell you how thankful I am for that.

To Dr. Sandrey

Your countless hours of work do not go unnoticed. You are one of the hardest working professors I have had the pleasure of working with and I truly admire that quality.

To Dr. McCrory \& Travis Randolph

Thank you for your time and dedication to this project. Your expertise in insight in your respective fields have improved the quality of this paper.

\section{To Dakota}

Thank you for the unconditional love and patience you have given to me during this time apart. Your support has kept me strong and focused. None of this would have been possible without you.

\section{To HealthWorks Clinical Staff}

Thank you for the professional support, knowledge, experience, and friendships gained during my time with you. I am a better athletic trainer because of you. 


\section{TABLE OF CONTENTS}

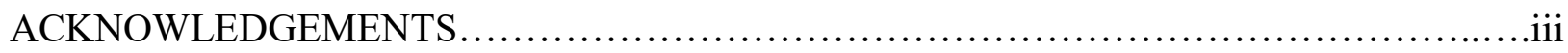

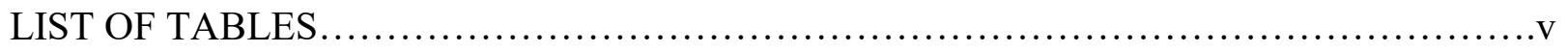

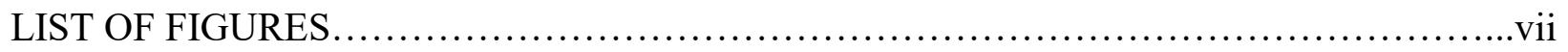

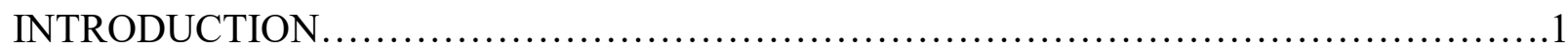

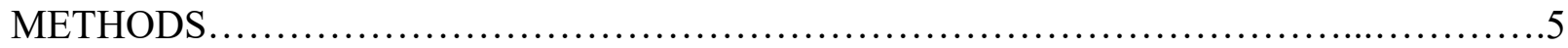

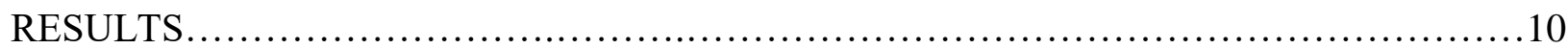

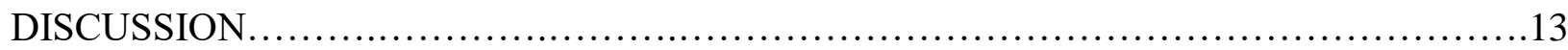

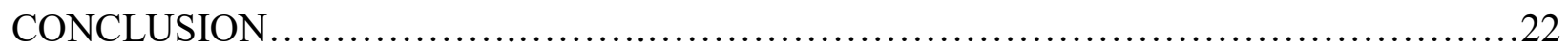

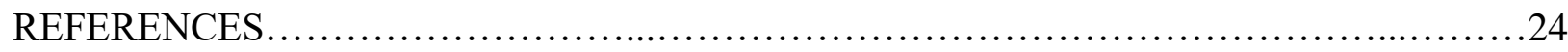

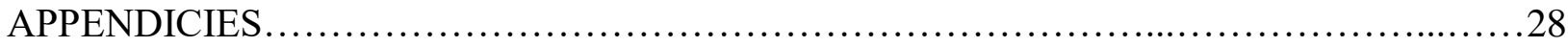

APPENDIX A. THE PROBLEM................................................. 29

APPENDIX B. LITERATURE REVIEW ..........................................

APPENDIX C. ADDITIONAL METHODS..........................................59

APPENDIX D. ADDITIONAL RSULTS ....................................... 74

APPENDIX E. RECOMMENDATIONS FOR FUTURE RESEARCH...................89

ADDITIONAL REFERENCES ......................................................... 90 


\section{LIST OF TABLES}

B1. Five Keys to Creating a Culture of Quality Improvement.............................45

B2. Nine Characteristics of a Quality System of Care for Nursing.........................47

B3. Appropriate Responsibilities of the Athletic Trainer..............................52

C1. Initial Cover Letter to Certified Athletic Trainers....................................59

C2. Follow-up Letter to Certified Athletic Trainers......................................60

C3. Final Notice Cover Letter to Certified Athletic Trainers...............................61

C4. Questionnaire to Division One Athletic Trainers...................................62

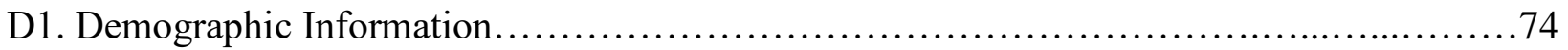

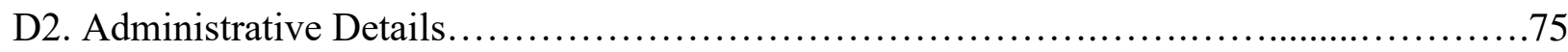

D3. Responsibilities as an Athletic Trainer....................................... 76

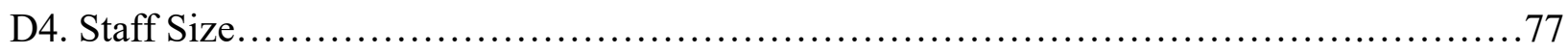

D5. Staff Size Average by Model..............................................77

D6. Full-Time Athletic Trainers by Model.......................................... 78

D7. Resident Athletic Trainers by Model............................................78

D8. Graduate Assistant Athletic Trainers by Model......................................78

D9. Intern Athletic Trainer by Model............................................78

D10. Coverage of NCAA Sports.................................................. 79

D11. Response to Survey Question Five.......................................... 80

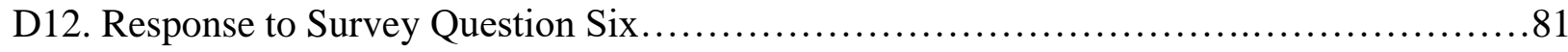

D13. Response to Survey Question Seven......................................... 82

D14. Response to Survey Question Eight....................................... 83

D15. Response to Survey Question Nine........................................... 84 


\section{LIST OF TABLES CONTINUED}

D16. Response to Survey Question Ten............................................84

D17. Response to Survey Question Eleven........................................... 85

D18. Likert Average by Category.................................................. 86

D19. Categorical Distribution........................................................ 86

D20. Quality of Care Category and Model of Organization.................................86

D21. Care Focus and Model of Organization......................................... 86

D22. Coverage Focus and Model of Organization..................................... 87 


\section{LIST OF FIGURES}

B1. Medicine's Triangle of Conflicting Expectations.....................................43

D1. NCAA Sports Receiving Care From Athletic Trainers................................88 


\section{INTRODUCTION}

Ethical expectations of all healthcare organizations require professionals to provide patients with the best possible care. ${ }^{1}$ The patient's best interest must always be the priority for a healthcare professional. ${ }^{1}$ Quality patient care is defined by Lopes Sauers et al. ${ }^{2}$ as "doing the right thing, at the right time, in the right way, for the right person, and having the best possible outcome". Each patient has a perspective of the ideal care received from healthcare professionals, thus, there is a lack of agreement on a criterion for measuring quality in healthcare. ${ }^{3}$ Since quality in health services increases the chance of receiving a desirable outcome at the population and the individual levels, ${ }^{1,4}$ it is not quality care to simple carry out an intervention or treatment. Rather, how the treatment or intervention is delivered to the patient should be the concern. ${ }^{3}$ To change the culture in a workplace, quality improvement (QI) should be adopted.

Healthcare worldwide has always strived to improve the quality of the care that is delivered to the patient. Quality Improvement is a necessary guide to administrators and clinicians alike, to continuously improve the care provided to patients. ${ }^{2}$ Batalden et al. ${ }^{5}$ described QI as "the combined effort of healthcare professionals, patients, researchers, payers, planners, and educators to make the changes that will lead to better patient outcomes, better system performance, and better professional development". Improving the system of care results in improvements in patients care. ${ }^{6}$

There is a massive healthcare reform happening in the United States. The focus of this reform is toward the delivery of quality healthcare that is reasonable in cost. ${ }^{7}$ The healthcare system in the United States is shifting away from fee-for-service toward a value-based system. ${ }^{2}$ The value of a healthcare service is increased when the quality increases and the cost decreases. ${ }^{2}$ 
The factors that go into quality healthcare include clinical care, functionality, cost, and satisfaction. ${ }^{8}$

Other healthcare fields have made correlations between staffing structure and the quality of care provided to patients. The direction of research in the nursing field has moved away from assessing operational costs. ${ }^{4}$ Instead, research has focused on increasing the quality of the care and how effectively organizations can use the resources available. ${ }^{4}$ When nursing shortages occur, an overall decrease in quality of patient care and an increase in medical errors occurred. ${ }^{9}$ It has been noted that the nurse to patient ratio has an inverse relationship with adverse health events such as infection and death. ${ }^{10}$ The more nurses on staff, the less adverse events occur and the higher quality of care being delivered to the patient.

In physical therapy, QI might not be related to the physical therapist to patient ratio, but rather to the amount of time spent with the patients. Expert physical therapists spend more time with patients compared to novice peers. ${ }^{11}$ The expert physical therapist can deliver more handson treatment, obtain more information, and further evaluate and educate the patients. ${ }^{11}$ Expert physical therapists are separated from novice peers by patient-centered approach to practice. ${ }^{11}$

Patient care in physical therapy has revolved around patient questionnaires. The development of a patient questionnaire highlights the domains of patient care in physical therapy. ${ }^{12}$ The use of a patient questionnaire has undergone a change as organizations no longer ask for the opinion of the patients, but rather ask the patients for subjective information regarding experience with the healthcare services received. ${ }^{13}$ Physical therapists use patient satisfaction questionnaires to evaluate the quality of the care provided and the facilities where care is delivered. ${ }^{12}$ In theory, as a result of patient satisfaction questionnaires, changes could be made to the manner in which care is delivered and the quality of facility where care is delivered. 
Organizational infrastructure in healthcare can affect quality of care. This raises the question: can changes be made in athletic training if a similar model used in healthcare is followed, such as the adaptation of a patient-centered model? Athletic trainers currently do not practice in a patient-centered model of organization like physical therapists. Also, athletic trainers do not have staffing standards or minimum patient ratios as is evident in the nursing field. Other healthcare professions have made QI a priority by increasing the quality of care delivered to patients. The profession of athletic training should consider what has occurred in the nursing and physical therapy profession to increase the quality of care delivered to student athletes.

Quality of care in the athletic training field may be dictated by the models of organizational infrastructure. In some cases, coverage may be stressed more than the care the athlete receives. There are three models of organizational infrastructure in the college/university athletic training setting: academic, athletic, and medical. ${ }^{14}$ The academic model employs athletic trainers who may serve multiple roles, clinical responsibilities and teaching responsibilities. ${ }^{14}$ Athletic trainers in the academic model report directly to an academic dean or to a department chair. ${ }^{15}$ The athletics model employs athletic trainers through the athletic department. ${ }^{14}$ The clinical staff are hired and fired by the athletic department. ${ }^{16}$ In most cases an athletic director who has no medical experience is supervising the athletic trainers. ${ }^{16}$ The third model is the medical model. Athletic trainers are employed through the school's health services center. ${ }^{15}$ The athletic trainers report to a physician within the health services center in the medical model. ${ }^{15}$ Most colleges/universities use the athletics model to structure the athletic training staff. Current literature highlights many disadvantages to the athletics model and very few advantages. Chronic understaffing, quality control, and conflicts with athletic administrators have been issues 
within the athletics model. ${ }^{16}$ Quality improvement is difficult to achieve when the administrators do not understand the difference between care and coverage. ${ }^{16}$ The athletics model places an undocumented emphasis on coverage of athletic events (practices, strength/conditioning sessions, and/or competition). Athletic trainers in the athletics model spend hours of the work day away from the clinic, providing coverage more so than care.

There has been a recent shift in athletic training to the medical model. This model is also known as the "patient-centered" model. ${ }^{17}$ The medical model can increase coordination of care provided to athletes, which would allow for a higher quality of care. ${ }^{15,17}$ The medical model puts athletic trainers in a position to work for an individual who will always put the medical needs of the athletes first. As a result of increased coordination and an enhanced focus on medicine, the long hours will be shortened, and the focus will change from coverage to care, as the National Athletic Training Association (NATA) recommends. ${ }^{15,18}$ The medical model places an undocumented emphasis on patient care. The athletic trainers spend work hours in the clinic, providing treatment, thoroughly documenting, continuing education, and collaborating with other healthcare professionals. The medical model fosters an environment for continued QI for the patients.

Quality improvement in athletic training is necessary to improve the value of the service provided. ${ }^{2}$ However, quality improvement in the field of athletic training has been limited, thus, little exists in the literature evaluating the quality of care athletic trainers provide to patients. ${ }^{2}$ The organizational models of the colleges and universities can have an impact on the athletic trainer to athlete ratio. ${ }^{14-17}$ The organizational models can also affect the priorities (coverage versus care) of the athletic trainers working for the colleges and universities. ${ }^{14-17}$ In the literature, organizational models have been evaluated but have focused on work-life balance as opposed to 
quality of care. ${ }^{14-16}$ Quality of care literature in athletic training has related more to the athlete's perception rather than the athletic trainer, ${ }^{19-24}$ however no one has evaluated organizational models as related to quality of care. Further, there have been no studies evaluating coverage versus care as it relates to the organizational models. The purpose of the current study is to find differences in the three models of organization (academic, athletic, and medical) as related to quality of care and focus (coverage or care).

\section{METHODS}

Design

This was a prospective descriptive exploratory study that included data collected from a 52-item online questionnaire. The participants were asked Likert scale questions evaluating the current clinical practice. The models of organization the participants are currently working in was compared to the self-perception to deliver quality healthcare to the student-athletes and whether a focus on coverage or care exists.

\section{Participants}

The participants of this study were randomly selected via the National Athletic Trainers' Association Research Survey Service. A sample of 1,000 randomly selected National Athletic Trainers' Association (NATA) certified members who are clinically active at a National Collegiate Athletic Association (NCAA) Division I institution were selected for participation. Participants were included from all 10 NATA districts to reduce the chance for geographical bias. Participants were included in this study if they are 18 years of age or older, are a NATABOC certified athletic trainer, and are currently practicing in the NCAA Division I setting. Excluded from this study was any participant who failed to meet the inclusion criteria or is working in a part-time or temporary (graduate assistant, interns or residents) capacity. There 
were 66 valid responses recorded from the 1,000 potential participants ( $0.06 \%$ return rate). Acknowledgment of this study was on file by the institutions Office of Research Compliance and Integrity.

Instrumentation

The questionnaire was developed through a review of relevant literature by examining questions utilized in previous studies of organizational models and quality of healthcare in athletic training. ${ }^{14,20,24-30}$ The purpose of the questionnaire was to gauge the self-perception of the quality of healthcare the participants deliver to the student-athletes based on organizational models. Furthermore, the questionnaire evaluated the focus (coverage and care) in the workplace. The questionnaire included sections for quality care, focus, and demographics. The quality care section has 22 Likert scale statements (3 reverse coded), using strongly disagree, somewhat disagree, neutral, somewhat agree, or strongly agree with the statement. Reverse coded questions were included to identify if participants are being consistent with the responses. Topics within the section included job responsibilities and completion of those responsibilities, availability to patients, colleagues and support staff, athletic training staff collaboration and job sharing, and supervisor's organization and distribution of responsibility. The focus section had 10 Likert scale statements which asked the participant to complete the statement "I am (blank)..." Options for response to these questions include very dissatisfied, somewhat dissatisfied, neutral, somewhat satisfied, very satisfied.

The demographics section will be placed at the end of the questionnaire to avoid participant fatigue. There were 20 demographic questions. Questions in the demographic section included forced choice questions and fill in the blank for gender, years as a Board of Certification (BOC) athletic trainer, years working in Division 1 setting, NATA district, position 
title, highest degree earned, professional credentials, number of athletes the participant is responsible for, number of athletic trainers on staff (Full time, graduate assistant, intern, resident), coverage of practice/events on campus, sports supervised by athletic trainers, hours of work per week (in-season and out of season), professional responsibilities, current model of organization, and title of supervisor and director of department.

The questionnaire was reviewed by three certified athletic trainers for readability and clarity. The questionnaire was pilot tested by graduate athletic training students prior to distribution. A psychometric expert experienced in research, questionnaires, and surveys assisted in the development of the survey and reviewed for content and face validity. Changes to the questionnaire were made after being reviewed, piloted, and tested for validity. After the changes were made, the final questionnaire was sent to the NATA Research Survey Service for distribution.

Procedures

After approval by the NATA District III Board of Directors, an e-mail was sent to NATA-BOC certified athletic trainers. There was a random sample of 1,000 certified athletic trainers selected by the NATA Research Survey Service. The prospective participants were contacted and hyperlinks to the questionnaire were distributed by the Research Survey Service. The hyperlink to the questionnaire was sent via e-mail to the certified athletic trainer. The e-mail included a brief description of the study and a link that directed the participant to Qualtrics Survey Software (Provo, UT). At that time participants were prompted with the cover letter (Table C1) explaining the procedures of the questionnaire, what directions to follow assuming the athletic trainer is willing to participate, and the rights of the participant. Immediately following the cover letter, the participants were prompted to continue to the survey or not. A 
follow-up e-mail was sent via the NATA Research Survey Service to all participants approximately 8 days after the initial e-mail to further encourage participation in the study (Table C2). A third e-mail was sent by the NATA Research Survey seven days prior to the survey closure date to further encourage participation in the survey. The participants were initially contacted on February 12, 2019.

Qualtrics recognizes "Confidential Information" as:

Terms, Orders, other agreements between the customer and Qualtrics, business and marketing plans and strategies, non-public business and technology information, trade secrets, Data, any written materials marked as confidential, and any other information, including visual and oral information, which reasonably should be understood to be confidential. The customer and Qualtrics will use commercially reasonable efforts, including appropriate technology and industry practices, to ensure the confidentiality, integrity, and security of all Confidential Information. To the extent allowed by law, the author agrees to indemnify and hold Qualtrics, and if applicable, the licensors and affiliates and each of their officers, directors, employees, and agents harmless against any and all claims and expenses, including reasonable attorneys' fees, arising from the use of the Services. This indemnification expressly includes the authors responsibility for any and all liability arising from the violation or infringement of copyrights, trademarks, or other proprietary rights and from the use of any libelous or unlawful material contained within the authors Data. ${ }^{31}$

Qualtrics' most important concern is:

...The protection and reliability of Customer data. The Qualtrics servers are protected by high-end firewall systems, and scans are performed regularly to ensure that any vulnerabilities are quickly found and patched. Complete penetration tests are performed yearly. All services have quick failover points and redundant hardware, with complete 
backups performed nightly. Qualtrics uses Transport Layer Security (TLS) encryption (also known as HTTPS) for all transmitted data. Surveys may be protected with passwords and HTTP referrer checking. The Qualtrics services are hosted by trusted data centers that are independently audited using the industry standard SSAE-16 method. ${ }^{32}$

Data Analysis

Likert scale questions were assessed by assigning a category (high quality, low quality) for the response to quality of care questions, high care or low care for the care focus questions, and high coverage or low coverage for the coverage focus questions. Participants were placed in the high-quality care category with a mean score of 3.5 or higher in the quality of care section (Questions 5-9 in Table C4). Participants were placed in the low-quality care category with a mean score lower than 3.5 in the quality of care section. The quality of care section had three reverse coded questions. The scoring was reversed for those questions, high-quality care for "Somewhat disagree" (4-points) and "Strongly disagree" (5-points) and low-quality care for "Somewhat agree" (2-points) and "Strongly agree" (1-point). Participants were placed in the high-coverage category with a mean score of 3.5 or higher in the coverage focus section (Question 11 in Table C4). Participants were placed in the high-care category with a mean score of 3.5 or higher in the care focus section (Question 10 in Table C4). Participants were placed in the low-care category with a mean score lower than 3.5 in the care focus section. The participants categories were compared to the organizational model which the participant worked in.

Statistical Analyses

Descriptive statistics were conducted including means and frequencies. A Fisher's Exact test was performed to determine a likelihood of demonstrating common themes among athletic trainers' model of organization based on quality of care, care focus, and coverage focus. A Chi 
Squared test could not be run because there were less than five entries in more than one of the cells. Therefore, a Fisher's Exact Test was most appropriate. There were three separate Fisher's Exact analyses run, model of organization to the quality of care category, model of organization to the care focus category, and model of organization to the coverage focus category. Dependent variables were the quality of category, care focus category, and coverage focus category. The independent variable was the model of organization. A $\mathrm{P}$-value of $\mathrm{P}=0.05$ was used for all analysis. All statistical analyses were run using IBM-SPSS Version 24.0 for Windows (IBMSPSS, Chicago, IL.)

\section{RESULTS}

Demographic

There were 83 surveys returned in this study. Nine surveys were not completed and eight did not meet the inclusion criteria. There were 66 valid surveys $(0.06 \%)$ to analyze. The gender of the participants was distributed somewhat equally at 53\% male (n=35) and $47 \%$ female $(n=31)$. All $(100 \%, n=66)$ participants in this study hold the credential of ATC. From the 66 participants, 33.3\% $(n=22)$ have been a certified athletic trainer for 0-4 years. Ninety-four percent $(n=61)$ of the participants held a master's degree as the highest degree. See Table D1 for additional demographic information.

Model of Organization

The participants were not evenly distributed across the three models of organization. Eighty-six percent $(n=57)$ were categorized into the athletics model, $10.6 \%(n=7)$ into the medical model, and $3.0 \%(n=2)$ into the academic model. Half $(50 \%, n=33)$ of the participants held a position title of Assistant or Associate Athletic Trainer at their place of employment. More than half $(56.1 \%, \mathrm{n}=37)$ of the participants work $60-79$ hours per week on average when 
supervising a sport that is "in-season". When in the "off-season", 60.9\% $(n=40)$ work 41-59 hours per week on average. Twenty-eight percent $(n=19)$ of the participants were individually responsible for the healthcare of more than 100 student-athletes throughout the course of an academic year. For additional results relating to athletic trainers' responsibilities and administrative details, please see Tables D2 and D3.

There were more than 20 administrative duties the participants could have chosen from. The three administrative duties that were most common among this sample was "Medical Records and Injury Reporting” (93.9\%, n=62), "Pre-participation physical examinations" $(81.8 \%, \mathrm{n}=54)$, and "Clinical Supervisor/Instructor to AT Students" (59.1\%, $\mathrm{n}=39)$. The composition of the staff by position included full-time ATs, Resident ATs, Graduate Assistant ATs, and Intern ATs. Thirty-nine percent $(n=26)$ of participants reported working in a staff of more than 10 full-time ATs. Only 7.6\% (n=5) reported having resident ATs on staff. Most participants $(54.5 \%, \mathrm{n}=36)$ do not work with any graduate assistant athletic trainers. Only $33.3 \%$ of participants reported having any Intern ATs on staff. The medical model had the largest average staff size (12.71 ATs, Full-time, resident, GA, and intern combined). The athletics and academic models had 10.64 and 11.5 total combined AT respectively. For more information on staff size, see Table D4-D9.

A majority $(56.1 \%, n=37)$ of participants reported athletic trainers cover all practices and games for NCAA sanctioned sports. There were 31 sports that received healthcare from a certified athletic trainer. The most reported sports were basketball $(97.0 \%, \mathrm{n}=64)$ and soccer (97.0\%, $\mathrm{n}=64)$. For more information on coverage, see Table D10. 
Quality of Care

The Quality of Care questions were scored on a Likert scale. A response of "Strongly disagree" was scored with one point, and a response of "Strongly agree" was scored with five points. Sixty percent $(n=40)$ of participants had a mean score of 3.00-3.99 in the Quality of Care section. Each response score was categorized based on the mean score of the Quality of Care section. A mean score of less than 3.5 was categorized as Low Quality. A score of 3.5 or more was categorized as High Quality. Seventy-four percent $(n=49)$ of participants were placed in the High-Quality category. For response rate to specific questions in the Quality of Care section, see Tables D11-D15.

Focus

The Focus questions were scored on a Likert scale. A response of "Very Dissatisfied" was scored with one point, and a response of "Very Satisfied" was scored with five points. In the Care section, $60.6 \%(n=40)$ of participants had a mean score of 4.00-5.00. In the Coverage section, $68.2 \%(n=45)$ of participants had a mean score of 4.00-5.00. Each participant was categorized based on the mean score of the Care section and the Coverage section. A mean score of less than 3.5 was categorized as Low Care/Coverage. A score of 3.5 or more was categorized as High Care/Coverage. Seventy-seven percent $(n=51)$ of participants were placed in the High Care category. Eighty percent $(n=53)$ of participants were placed in the High Coverage category. For response rate to specific question in the Focus section, see Tables D16 and D17. Fisher's Exact Test

Fisher's Exact Test were completed to understand the relationships between the model of organization (Athletics, Medical or Academic) and the quality of care category and focus (Care and Coverage) category of the participants. A Chi square could not be run because there were 
less than five data entries into more than one of the cells. All three Fisher's Exact Tests were two-sided tests. There was a significant $\left(\sum=6.614, \mathrm{p}=.021\right)$ relationship between the model of organization and the quality of care category. The relationship between model of organization and the focus categories was not significant, care $\left(\sum=1.426, \mathrm{p}=.608\right)$ and coverage $\left(\sum=0.357\right.$, $\mathrm{p}=1.000$ ). For more information on the Fisher's Exact test, see Tables D20-D22.

\section{DISCUSSION}

The purpose of the current study was to find differences in the three models of organization (academic, athletic, and medical) as related to quality of care and focus (coverage or care). The models of organization the participants are currently working in was compared to the self-perception to deliver quality healthcare to the student-athletes and whether a focus on coverage or care exists. There were 66 valid responses to the survey. Of the 66 responses, $86.4 \%$ of the athletic trainers are practicing in the athletics model of organization. Despite most participants in the athletics model, $74.2 \%$ of all participants view the quality of care delivered as high-quality. There was $80.3 \%$ of participants in the high-coverage category and $77.3 \%$ of participants in the high-care category. With more than $75 \%$ of participants fitting into both the high-coverage and high-care category, coverage and care in athletic training are not mutually exclusive or present with an inverse relationship.

There were five experimental hypotheses for this study. The first hypothesis stated that there would be more athletic trainers practicing in the athletics model than the other two models of organization. That hypothesis has been accepted, $86.4 \%$ of participants were in the athletics model. The second hypothesis stated there would be more medical model participants in the high-quality care category than the other two models. This hypothesis has been accepted, 100\% of medical model participants were in the high-quality care category. This should be interpreted 
with caution as the sample size for the medical model was only 7 . The third hypothesis stated there would be more athletics model athletic trainers in the low-quality care category than the other two models. This hypothesis has been rejected, only $26.3 \%$ of the athletics model athletic trainers categorized as low-quality care, the academic model had a higher percent of athletic trainers in the low-quality care category (100\%). This hypothesis should also be interpreted with caution because the sample size for the academic model was only 2 . The fourth hypothesis stated there would be more athletics model athletic trainers in the high-coverage category when compared to the other two categories. This hypothesis has been rejected, as the athletics model had the lowest average of participants in the high-coverage category. However, with low number in the medical model and academic model, this should be interpreted with caution. The last hypothesis stated there would be more medical model athletic trainers in the high-care category when compared to the other two models. This hypothesis has been accepted; the medical model had $85.7 \%$ of the participants categorized as high-care based on responses.

\section{Models of Organization}

There are three models of organizational infrastructure in the college/university athletic training setting: academic, athletic, and medical. ${ }^{14}$ The academic model employs athletic trainers who may serve multiple roles, clinical responsibilities and teaching responsibilities. ${ }^{14}$ Athletic trainers in the academic model report directly to an academic dean or to a department chair. ${ }^{15}$ The athletics model employs athletic trainers through the athletic department. ${ }^{14}$ The clinical staff are hired and fired by the athletic department. ${ }^{16}$ In most cases an athletic director who has no medical experience is supervising the athletic trainers. ${ }^{16}$ The third model is the medical model. Athletic trainers are employed through the school's health services center. ${ }^{15}$ The athletic trainers 
report to a physician within the health services center in the medical model. ${ }^{15}$ This model is also known as the "patient-centered" model. ${ }^{17}$

Both the medical model and academic models were used in the NCAA Division I.

However, it cannot be determined whether the numbers are lower than the athletics model as the response rate was limited for those two categories. Perhaps this may be related to the fact that either of those did not want to be identified with high-coverage or low-care categories. Use of the medical model is being advocated by the National Athletic Trainers Associations (NATA) and the topic has become very popular in terms of discussion by athletic trainers. In fact, the NATA is currently conducting a survey on the use of the medical model in athletic training.

The medical model is beginning to be used, but it is not as often as the athletics models. The supervisors position titles of the participants suggest that a transition may have started as there is currently a hybrid model between the use of the athletics and medical models. There were three participants that reported a supervisor position title being directly related to the medical model: Team physician, Associate Director of Medical Services and Director of Health Sciences School. The use of the medical model requires the sports medicine staff to be an employee of the student health center or in some cases a hospital associated with the institution. These healthcare networks often require patient reported outcome measures or a long list of training procedures that may take time away from the patients. The investigators question whether the quality improvement goals of the medical model are too difficult to achieve, leaving no choice but to stay within the athletics model and improve the quality of care within that structure. It is up to the individual institutions sports medicine departments to evaluate the possibility of joining the student health center, and whether the benefits outweigh the barriers. 
The investigators have found the athletics model is currently being widely used by much of the sample (86.4\%). The available literature is congruent, most colleges and universities operate in the athletics model. ${ }^{16}$ This could be true because many of the NCAA Division I Power Five Conference schools athletic departments have the capital to allow the sports medicine department to update equipment and facilities, and hire more staff members which creates a "pseudo-medical model" or a hybrid between athletics and medical models. Current literature highlights many disadvantages to the athletics model and very few advantages. Chronic understaffing, quality control, and conflicts with athletic administrators have been concerns within the athletics model. ${ }^{16}$ The academic model may not be used as frequently as in the past. This may be due to the development of a separation between the academic and athletic departments, where the athletic department are seen as a stand-alone entity, almost like a corporation. Further, the academic model has proven to not be congruent with a healthy worklife balance. ${ }^{14,15,33}$ Athletic training educators have been required to work up to 75 hours per week with providing coverage and care to the student athletes, this does not include the classroom instruction requirements that need to be fulfilled. ${ }^{33}$

The question for each individual institution is to decide what model, or hybrid of the three models allows for independent medical care of the student-athlete and gives those medical care providers unchallengeable autonomous authority to provide that independent medical care. This goal can be delivered by any of the models. Regardless of which model of organization an athletic trainer is employed in, quality of healthcare is ultimately the top priority and that no coach or athletic director provide any influence on that decision. There are barriers embedded within each model, but the care delivered by the athletic trainers and team physicians need to be independent of all athletic department personnel. It may not be feasible for a small liberal arts 
institution to associate with a well-established student health center. In which case, the small liberal arts institution would need to use the athletics model. While in that model, the sports medicine staff need to educate administrators that the athletic trainers and team physicians will be the only decision makers when it comes to the health and safety of the student athletes within the department, thus providing independent care. Before advocating for the use of the medical model or the elimination of the athletics model, further research is warranted.

Quality of Care

Healthcare professionals strive to provide patients with the best possible care. ${ }^{1}$ The patient's best interest is always the top priority for the healthcare professional. ${ }^{1}$ Healthcare worldwide has always strived to improve the quality of the care that is delivered to the patient. ${ }^{2}$ A patient-centered model of healthcare delivery, such as the medical model, places the needs of the individual patient at the forefront for all healthcare professionals involved. ${ }^{17}$ Improving the system of care results in improvements in patients care. ${ }^{6}$ Quality improvement requires a team that is committed to continuously improve the patient's care, has support from leadership, and has an accurate understanding of the system and the patients within the system. ${ }^{34}$ However, the current practice of athletic training makes it difficult to objectively measure patient outcomes and patient satisfaction. With infrastructure organizational administrative changes, the profession of athletic training in the collegiate setting could align the profession to follow along with nursing and physical therapy from a QI perceptive. The nursing profession has undergone changes to improve the nurse to patient ratio. ${ }^{35}$ It has been found that patient outcomes improve if the nurses are adequately staffed. ${ }^{35,36}$ In physical therapy, patient satisfaction questionnaires are used to change and improve the care given by physical therapists. ${ }^{12}$ Physical therapists have improved by spending more time with the patient, listening, educating, and evaluating. ${ }^{11}$ 
Quality improvement is a way for organizations and healthcare professionals to work smarter and make jobs easier. ${ }^{37}$ The greatest barrier to creating a QI culture is leadership in the organization. ${ }^{38}$ Furthermore, if QI culture is adopted and the wellbeing of the patient is the top priority, the model of organization the athletic trainer is employed in should not be a factor. Sixty-one percent of participants in the present study reported team physicians are not involved in the evaluation of the performance of athletic trainers. Involving team physicians in the evaluation of athletic trainers would show the staff that the organization is committed to improving the quality of care provided to patients. Only $43.9 \%$ of participants felt the supervisor was creative in reallocating job responsibilities to help the staff work better as a team. Similarly, only $46.9 \%$ of participants felt the division of responsibility worked well. Cultural change needs to occur along with the reorganization of staff and management to provide a culture where quality care is the top priority. ${ }^{39}$ Supervisors should be willing to reallocate job responsibilities as needed to better disperse the workload among all members of the sports medicine team. The investigators believe athletic trainers self-perception of the care delivered is very high even though $57 \%$ of the participants felt they did not complete all tasks required of them. Further, athletic trainers believe that coverage and administrative duties do not affect the quality of care delivered.

Coverage Versus Care

The workload for athletic trainers in the college/university setting is gradually increasing. ${ }^{40,41}$ Increases in participation time for each team equates to more exposures for injury. ${ }^{42}$ Unfortunately, the athletic trainer to athlete ratio has not decreased. In 2014, in South Carolina, there was an athletic trainer-athlete ratio of 1:87 at all collegiate levels. ${ }^{43}$ Twenty-eight percent of respondents reported they were directly responsible for the healthcare for more than 
100 student athletes. Furthermore, the hours worked per week and the athlete-athletic trainer ratio is directly related to the size of the sports medicine staff. The participants of this study reported a high number of full-time athletic trainers on staff. Thirty-nine percent of the participants reported working on a staff of 10 or more full-time athletic trainers. The medical model had the largest average combined staff (Full-time, resident, GA, and intern). The medical model had an average of 12.71 ATs combined in all positions. The athletics and academic model had combined staff sizes of 10.64 and 11.50 ATs respectively. One of the known benefits to the medical model is larger staff sizes to disperse the work load among more athletic trainers. ${ }^{15,17} \mathrm{~A}$ larger staff also creates the opportunity for more professional collaboration on patient cases. ${ }^{15,17}$, ${ }^{44-46}$ Despite the disproportionate athlete to athletic trainer ratio, a majority of participants felt satisfied with the care delivered (95.4\%), the hours of operation in the athletic training room (78.8\%), the equipment available (66.7\%), and the amount of supplies available (80.3\%). These have all been identified as characteristics of quality healthcare. ${ }^{4,47,48}$ The amount of time that staff members spend with patients and listen to patients has also been identified as a factor. ${ }^{49,50}$ Almost $80 \%$ of participants felt satisfied with the operational hours of their AT room as it relates to the quality of patient care.

Fifty-six percent of participants of the present study expressed that they work 60-79 hours per week while their team is "in-season". When in "off-season", $60.6 \%$ of participants worked an average of 41-59 hours per week. The number of hours worked per week is directly related to the number of athletes the participants are directly responsible for. The average staff size in the Football Bowel Series (FBS) of NCAA Division I is nine full time ATs. ${ }^{44}$ Only one third of FBS schools have enough full time ATs to cover football. ${ }^{45}$ In all of DI athletics in the NCAA, ATs are responsible for at least three athletic teams and 90 or more student-athletes. ${ }^{41}$ 
Most school's employ only seven full time ATs and sponsor between 20 and 28 sports. $^{41}$ Mazerolle et al. ${ }^{41}$ evaluated the DI setting in regard to the size of staff and whether the staff was large enough to fulfill all the responsibilities of a program at that level. Seventy-eight percent responded with "no". Athletic trainers work up to 80 hours a week during a sport season to provide medical care, traveling with the team, and fulfilling administrative duties. ${ }^{14,28}$

Athletic trainers have unique responsibilities within the healthcare field. A collegiate athletic trainer is responsible for the healthcare of all athletes on the rosters of a team or several teams depending on the institution. The NATA released a publication in 2007 describing the appropriate coverage of intercollegiate athletics. ${ }^{30}$ Described within the publication is the definition of appropriate responsibilities of the athletic trainer outside the role of practice and event coverage. (Table B3) Despite the recommendations, AT's still appear to spend more time with coverage as many organizations require their athletic trainers to be physically present at all practices and to travel with teams to away contests. ${ }^{30}$ Thus, connecting care with coverage, which many not have been the original intent of the document. The participants were overall satisfied with the time spent at practice $(81.8 \%)$, initial response time to injuries $(97.0 \%)$, and the athletic trainers' location during practices and games $(93.9 \%)$.

The NCAA is now allowing football and men's and women's basketball programs to require athletes to participate in up to eight hours a week of team activities in the summer months. ${ }^{28}$ According to the NATA recommendations, those activities must be covered by an AT. ${ }^{30}$ Also, more exposure (practices and other team activities) equates to more injuries. ${ }^{16,28}$ Participants were overall less satisfied with the coverage of summer (54.5\%), pre-season (74.2\%), and post-season (68.1\%) conditioning and skills sessions. 
In addition to event and practice coverage, athletic trainers often have responsibilities such as injury prevention programs, treatment and rehabilitation of injuries and illnesses, return to play decision making, nutrition and psychosocial treatment and referral, documentation, and continuing education. ${ }^{30}$ Participants reported 20 different administrative responsibilities. The highest reported duties were medical records and injury reporting (93.9\%), pre-participation physicals (81.8\%), and clinical supervision of AT students (59.1\%).

\section{Clinical Implications}

The investigators have identified that high quality care is possible in the athletics model of organization. This could be due to a hybrid model between the athletics model and the medical model. For example, a small liberal arts school would not benefit from associating with the under established student health center at the institution. When athletic trainers in the athletics model collaborate with patient care, meaning more than one athletic trainer working with individual patients to enhance quality, and the team physicians are involved in the quality improvement of the department, then the athletics model will operate like a medical model from a quality standpoint.

For ATs, quality medical care must be the top priority in times of conflict with coaches or athletic administrators. ${ }^{46}$ Coaches should never be a supervisor to the member of the sports medicine team, nor should they be involved in the appointment or employment of sports medicine staff members. ${ }^{46}$ Schools should have a line of unchallengeable authority for the team physician and athletic trainers to make medical decisions without input from coaches or athletic administrators. ${ }^{46}$ At the collegiate level there should be a healthcare professional (team physician or head AT) as a senior level athletic administrator. ${ }^{46}$ This person can prioritize the health, safety, 
and welfare of all athletes as well as have an input in budget, risk management, institutional liability, quality assurance, and athlete satisfaction. ${ }^{46}$

The medical model of organization does not eliminate coverage of practices and events from the duties of athletic trainers. Athletic trainers in the medical model provide a higher quality healthcare, but they also cover events to decrease the response time to an athletic injury or emergency. Athletic trainers in the medical model may have additional barriers, depending on the company. Some companies my require an evaluation of care delivered annually. To measure care provided, athletic trainers would have to ask patients to fill out patient-oriented outcomes measures and/or patient satisfaction questionnaires. The former has been difficult to implement in the athletic arena in the past. The medical model may be the gold standard for work-life balance, but that topic is outside the scope of this study.

If the medical model is adopted, and the patient is considered the number one priority, then patient reported outcomes measures should be included and evaluated on a constant and annual basis. Improving the system of care results in improvements in patient' care. ${ }^{6}$ Quality improvement requires a team that is committed to continuously improve the patients care, has support from leadership, and has an accurate understanding of the system and the patients within the system. ${ }^{34}$ In some cases modifying the existing athletic training structure and operation should be considered. Operational policies that can be adjusted include hours of operation, traditional versus non-traditional season coverage, travel expectations, and schedule changes of practices and events with appropriate advanced notice. ${ }^{15,17}$ Supervisors can assess the workload of all ATs on staff and encourage job sharing. ${ }^{15}$ Job sharing, is when other ATs cover events when the primary AT is not available for any reason. ${ }^{15}$ The sports medicine department should provide employees with time and compensation for staff members to attend professional 
conferences for continuing education. ${ }^{15}$ The supervisor should also advocate to the athletic administration for higher salaries that correlate to job responsibilities and for more full-time staff member to reduce the workload of the current staff. ${ }^{15,17}$

\section{Limitations}

The investigators have acknowledged the sample size of the study is the primary limitation to the strength of the study. Without an even distribution of athletic trainers in all three models of organization it is difficult to truly analyze the strengths and weaknesses of each model from a quality of care standpoint. This survey was limited by the self-perception of the participants. Some participants may have been inclined to over report the quality of care truly delivered.

\section{CONCLUSION}

The quality of care athletic trainers deliver was found to be significantly related to the athletic trainer's model of organization. Of the three models of organization, the athletics model still has a strong presence in the NCAA Division One setting for athletic trainers. Overall, athletic trainers perceived the care delivered was high in quality. Despite delivering high-quality care, the athletic trainers are still covering practices and events. The athletic trainers in the medical model delivered high-quality care, more than the athletics and academic models. The academic model delivered the lowest-quality care.

Quality of care in athletic training relies on athletic trainers' base of knowledge, colleagues, and the facility/equipment available to them. Though the medical model may increase the chances of delivering high-quality care, the athletics model also could provide highquality care to patients. 


\section{REFERENCES}

1. Brennan TA. Physicians' professional responsibility to improve the quality of care. Acad Med. 2002;77(10):973-980.

2. Lopes Sauers AD, Sauers EL, Snyder Valier AR. Quality improvement in athletic health care. J Athl Train. 2017;52(11):1070-1078.

3. Attree M. A study of the criteria used by healthcare professionals, managers and patients to represent and evaluate quality care. J Nurs Manag, 2001;9:67-78.

4. Campbell SM, Roland MO, Buetow SA. Defining quality of care. Soc Sci Med. 2000:51;1611-1625.

5. Batalden PB, Davidoff F. What is "quality improvement" and how can it transform healthcare? Qual Saf Health Care. 2007;16(1):2-3.

6. Ogrinc G, Headrick L, Moore S, Barton A, Dolansky M, Madigosky W. Fundamentals of health care improvement: A guide to improving your patients' care. 2nd ed. Oakbrook Terrance, IL: Joint Commission Resources; 2012.

7. Reducing costs and improving outcomes: research in action. Issue 8. Agency for Healthcare Research and Quality, Rockville, MD. http://archive.ahrq.gov/research/findings/factsheets/pharmaceutical/rxtherapies/rxria.html. Published September 2002. Accessed September 16, 2018.

8. Nelson EC, Mohr JJ, Batalden PB, Plume SK. Improving health care, part 1: the clinical value compass. Jt Comm J Quality Improv. 1996;22(4):243-258.

9. Garrett C. The effect of nurse staffing patterns on medical errors. Assoc Periop Reg Nurs. 2008;87(6):1191-1204.

10. Currie V, Harvey G, West E, McKenna H, Keeney S. Relationship between quality of care, staffing levels, skill mix and nurse autonomy: literature review. J Adv Nurs. 2005;51(1):7382.

11. Resnik L, Jensen GM. Using clinical outcomes to explore the theory of expert practice in physical therapy. Phys Ther. 2003;83(12):1090-1106.

12. Goldstein MS, Elliot SD, Guccione AA. The development of an instrument to measure satisfaction with physical therapy. Phys Ther. 2000:80(9);853-863.

13. Schlote M, Calsbeek H, Nijhuis-van der Sanden MWG, Braspenning J. Quality of physical therapy from a patients's perspective; factor analysis on web-based survey data revealed three dimensions on patient experiences with physical therapy. BMC Health Serv Res. 2014;14(266):1-8. 
14. Mazerolle SM, Eason CM, Goodman A. Organizational infrastructure in the collegiate athletic training setting, part I: Quality-of-life comparisons and commonalities among the models. J Athl Train. 2017;52(1):12-22.

15. Eason CM, Mazerolle SM, Goodman A. Organizational infrastructure in the collegiate athletic training setting part III: Benefits of and barriers in the medical and academic models. J Athl Train. 2017;52(1):35-44.

16. Goodman A, Mazerolle SM, Eason CM. Organizational infrastructure in the collegiate athletic training setting part II: Benefits of and barriers in the athletics model. $J$ Athl Train. 2017;52(1):23-34.

17. Laursen RM. A patient-centered model for delivery of athletic training services. Athl Ther Today. 2010;15(3):1-3.

18. Committee on Revenue, College/University Athletic Trainers' Committee, College Value Model Workgroup. College-University Value Model. Dallas, TX: National Athletic Trainers' Association; 2014. http://www.nata.org/sites/default/files/college-value-model.pdf. Accessed August 29, 2018.

19. Unruh S, Unruh N, Moorman M, Seshadri S. Collegiate student-athletes' satisfaction with athletic trainers. J Athl Train. 2005;40(1):52-55.

20. Porterfield JM, Biddington C. College athletes perceptions of care provided by certified athletic trainers. [Master Thesis]. California, PA: California University of Pennsylvania; 2006.

21. Foster CJ. Exploring athletes' perceptions of athletic trainers quality of care. [Master Thesis]. Las Vegas, NV: University of Nevada, Las Vegas; 2015.

22. Pilgrim JJ. Exploring collegiate student-athletes' satisfaction with athletic trainers. [Master Thesis]. East Lansing, MI: Michigan State University; 2010.

23. Beuhring BE. Perceptions of the athletic training profession by a collegiate athlete patient population. [Master Thesis]. Huntington, WV: Marshall University; 2017

24. Unruh S. The perception student-athletes have of their athletic trainers and the medical services provided them by the athletic departments at their institution. [Doctoral Dissertation]. Fayetteville, AR: University of Arkansas; 1996.

25. DeSimone T, West E. NATA district one and two certified athletic trainers' self-perceptions of satisfaction with athletic training care and work in relation to tenure at a workplace and overall experience. [Master Thesis]. California, PA: California Univeristy of Pennsylvania; 2016. 
26. Boehke MJ, Sorber N, Goeres E, Lefebvre L, Mamboleo G, Zimmerman E. Barriers, facilitators, and frequency of evidence based practice use in athletic training. [Doctoral Dissertation]. Morgantown, WV: West Virginia University; 2014.

27. Eason CM, Mazerolle SM, Pitney WA. Initial validation of a multilevel model of job satisfaction and career intentions among collegiate athletic trainers. J Athl Train. 2018;53(7):709-715.

28. Mazerolle SM, Eason CM, Goodman A. Exploring summer medical care within the national collegiate athletic association division I setting: A perspective from the athletic trainer. $J$ Athl Train. 2016;51(2):175-183.

29. Ray RR. Performance evaluation in athletic training: Perceptions of athletic trainers and their supervisors. [Doctoral Dissertation]. Kalamazoo, MI: Western Michigan University; 1990.

30. National Athletic Trainers Association. Recommendations and guidelines for appropriate medical coverage of intercollegiate athletics. National Athletic Trainers Association web site. https://www.nata.org/professional-interests/job-settings/collegeuniversity/resources/AMCIA. Revised June 2007. Accessed October 5, 2017.

31. Terms of Service. Qualtrics. https://www.qualtrics.com/terms-of-service/. Revised: November 26, 2018. Accessed: December 5, 2018.

32. Security Statement. Qualtrics. https://www.qualtrics.com/security-statement/. Published: July 13, 2018. Accessed: December 5, 2018.

33. Alley RC. A case study of athletic training educators' sports-care responsibilities, service, and professional advancement in athletic training education programs. [Doctoral Dissertation]. Huntington, WV: Marshall University; 2012.

34. Mills PD, Weeks WB. Characteristics of successful quality improvement teams: lessons from five collaborative projects in the VHA. Jt Comm J Qual Saf. 2004;30(3):152-162.

35. Mark BA, Harless DW, McCue M, Xu Y. A longitudinal examination of hospital registered nurse staffing and quality of care. Health Serv Res. 2004;39(2):279-300.

36. Harrington C, Schnelle JF, McGregor M, Simmons SF. The need for higher minimum staffing standards in U.S. nursing homes. Health Serv Insights. 2016:9;13-19.

37. Davis MV, Mahanna E, Joly B et al. Creating quality improvement culture in public health agencies. Am J Public Health. 2014:104(1);e98-e104.

38. Riley W, Parsons HM, Duffy GL, Moran JW, Henry B. Realizing transformational change through quality improvement in public health. J Public Health Manag Pract. 2010;16(1):7278 . 
39. Donaldson LJ, Muir Gray JA. Clinical governance: a quality duty for health organizations. Qual Health Care. 1998;7(Suppl):S37-44.

40. Goodman A, Mensch JM, Jay M, French KE, Mitchell MF, Fritz AL. Retention and attrition factors for female certified athletic trainers in the national collegiate athletic association division I football bowl subdivision setting. J Athl Train. 2010;45(3):287-298.

41. Mazerolle SM, Faghri P, Marcinick M, Milazzo S. Athletic trainers' workload in NCAA division I athletic programs. Athl Ther Today. 2010;15(3):34-37.

42. Powell JW, Dompier TP. Analysis of injury rates and treatment patterns for time-loss and non-time-loss injuries among collegiate students-athletes. J Athl Train. 2004;39(1):56-70.

43. Bradley R, Cromartie F, Briggs J, Battenfield F, Boulet J. Ratios of Certified Athletic Trainers' to Athletic Teams and Number of Athletes in South Carolina Collegiate Settings. Sport J. 2015:4

44. Gallucci AR, Peterson JC. The size and scope of collegiate athletic training facilities and staffing. J Athl Train. 2017:52(8);785-794.

45. Aparicio S, Welch Bacon CE, Parsons JT et al. Staffing levels of national collegiate athletic association football bowl subdivision-level institutions. J Athl Train. 2015:50(12);12771285.

46. Courson R, Goldenberg M, Adams KG et al. Inter-association consensus statement on best practice for sports medicine management for secondary schools and colleges. J Athl Train. 2014;49(1):128-137.

47. Yam B, Rossiter J. Caring in nursing: perceptions of hong kong nurses. J Clin Nurs. 2000;9:293-302.

48. Idvall E, Rooke L. Important aspects of nursing care in surgical wards as expressed by nurses. J Clin Nurs. 1998;7:512-520.

49. Jackson-Frankl M. The language and meaning of quality. Nurs Admin Q. 1990;14:52-65.

50. Parish S. Quality v quantity: which type of nursing do you practice? J Pract Nurs. 1986;36:30-31. 
APPENDICIES 


\section{APPENDIX A}

\section{THE PROBLEM}

\section{Research Question}

Ethical expectations of all healthcare organizations require professionals to provide their patients with the best possible care. ${ }^{1}$ The patient's best interest must always be the priority for a healthcare professional. ${ }^{1}$ Quality patient care is defined by Lopes Sauers et al. ${ }^{2}$ as "doing the right thing, at the right time, in the right way, for the right person- and having the best possible outcome". Each patient has a perspective on the ideal care received from healthcare professionals. However, there is a lack of agreement on a criterion for measuring quality in healthcare. ${ }^{3}$ Quality in health services increase the chance of receiving a desirable outcome at the population and the individual levels. ${ }^{1,4}$ Effective clinical care occurs when evidence-based practice is effectively applied. ${ }^{4}$ Effectiveness and access are two components to quality care. Effectiveness can be divided into two parts, clinical effectiveness and effectiveness of interpersonal care. ${ }^{4}$ It is not quality care to simply carry out an intervention or treatment. Rather, how the treatment or intervention is delivered to the patient determines quality of care. ${ }^{3}$ Interpersonal care is achieved when the healthcare professional spends time with the patient to listen to the needs of the patient and create a treatment plan that is individualized. ${ }^{3}$ The organizational structure of healthcare does not only consist of the staff and personnel. Also included in structure are equipment, facilities, hours of operation, and appointment booking system. ${ }^{3,4}$ All of the factors of organizational structure provide the patient with access to healthcare, but do not always guarantee the care will be high in quality. ${ }^{4}$ It is possible to have structural or cultural barriers to providing quality care to patients. ${ }^{51}$ The culture of the workplace is responsible for the values the employees hold, and how these values are judged and 
understood by the employees. ${ }^{51}$ To change the culture in a workplace, quality improvement (QI) should be adopted.

Healthcare worldwide has always strived to improve the quality of the care that is delivered to the patient. Quality Improvement is a necessary guide to administrators and clinicians alike, to continuously improve the care provided to patients. ${ }^{2}$ Batalden et al. ${ }^{5}$ describes QI as "the combined effort of healthcare professionals, patients, researchers, payers, planners, and educators to make the changes that will lead to better patient outcomes, better system performance, and better professional development". Improving the system of care results in improvements in patients care. ${ }^{6}$ Quality improvement requires a team that is committed to continuously improve the patients care, has support from leadership, and has an accurate understanding of the system and the patients within the system. ${ }^{51}$

There is a massive healthcare reform happening in the United States. The focus of this reform is toward the delivery of quality healthcare that is reasonable in cost. ${ }^{7}$ The healthcare system in the United States is shifting away from fee-for-service toward a value-based system. ${ }^{2}$ A fee-for-service model allows healthcare providers to place an emphasis on quantity rather than quality. Each treatment or procedure that is preformed, the clinician can be reimbursed for. This model directly impacts the income of the clinicians. ${ }^{52}$ Value-based systems reward clinicians for quality care. The value of a healthcare service is increased when the quality increases and the cost decreases. ${ }^{2}$ The factors that go into quality healthcare include clinical care, functionality, cost, and satisfaction. ${ }^{8} \mathrm{~A}$ clinician in the value-based system must do everything they can to create in individualized treatment plan for each patient and execute the plan in a timely, efficient manner. ${ }^{53}$ 
Other healthcare fields have made correlations between staffing structure and the quality of care provided to patients. The direction of research in the nursing field has moved away from assessing operational costs. ${ }^{4}$ Instead, research has focused on increasing the quality of the care and how effectively organizations can use the resources available. ${ }^{4}$ There was an overall decrease in quality of patient care and an increase in medical errors related to nursing shortages. ${ }^{9}$ The nurse to patient ratio has an inverse relationship with adverse health events such as infection and death. ${ }^{10}$ The more nurses on staff, the less adverse events occur. The more nurses on staff, the higher quality of care being delivered.

Experienced physical therapists spent more time with patients compared to novice peers. ${ }^{11}$ Because of this, more hands-on treatment, and information is obtained, which allows the physical therapist to further evaluate and educate the patients. ${ }^{11}$ Expert physical therapists are separated from the novice peers by the patient-centered approach to practice. ${ }^{11}$ Other studies have focused on involving the patient in the medical decision making and goal setting to improve outcomes and therefore improve the quality of the care delivered by physical therapists. ${ }^{54-57}$ Organizational infrastructure in healthcare can affect quality of care. This raises the question: can changes be made in athletic training if a similar model used in healthcare is followed, such as the adaptation of the medical model? Athletic trainers currently do not practice in a patient-centered model of organization like physical therapists. Also, athletic trainers do not have staffing standards or minimum patient ratios like the nursing field does. Other healthcare professions have made QI a priority by increasing the quality of care delivered to the patients. The profession of athletic training must follow the nursing and physical therapy profession to increase the quality of care delivered to student athletes. 
Quality improvement in athletic training is necessary to improve the value of the service provided. ${ }^{2}$ However, quality improvement in the field of athletic training has been limited. ${ }^{2}$ Literature evaluating the quality of care athletic trainers provide to patients is limited. ${ }^{2}$ Healthcare professionals who operate outside third-party reimbursement, such as athletic trainers, are not required to document and evaluate the quality of those factors. ${ }^{2}$ Establishing value with administrators can improve the care delivered and the facilities provided. Meaning, if the work athletic trainers do for the patient is viewed by administrators as valuable, the administrators would be willing to increase budgets, improve facilities, purchase new equipment, hire more staff, and increase wages. ${ }^{5}$

Quality of care in the athletic training field may be dictated by the models of organizational infrastructure. In some cases, coverage may be stressed more than the care the athlete receives. There are three models of organizational infrastructure in the college/university athletic training staffs, they are academic, athletic, and medical. ${ }^{14}$ The academic model employs athletic trainers who may serve multiple roles, clinical responsibilities and teaching responsibilities. ${ }^{14}$ Athletic trainers in the academic model report directly to an academic dean or to a department chair. ${ }^{15}$ The athletics model employs athletic trainers through the athletic department. ${ }^{14}$ The clinical staff are hired and fired by the athletic department. ${ }^{16}$ In most cases an athletic director who has no medical experience is supervising the athletic trainers. ${ }^{16}$ The third model is the medical model. Athletic trainers are employed through the school's health services center. ${ }^{15}$ The athletic trainers report to a physician within the health services center in the medical model. ${ }^{15}$

Most colleges/universities use the athletics model to structure the athletic training staff. Current literature highlights many disadvantages to the athletics model and very few advantages. 
One advantage is the close relationship and enhanced communication athletic trainers can achieve with athletic department personnel. ${ }^{46}$ Chronic understaffing, quality control, and conflicts with athletic administrators have been issues within the athletics model. ${ }^{16}$ Conflict with coaches and administrators places athletic trainers in a position of high pressure and stress. ${ }^{58}$ There have been many cases of athletic trainers being terminated because of disagreements over medical treatment or because of coaching staff changes. ${ }^{17,59}$ Chronic understaffing leads to long, demanding, and inflexible hours. ${ }^{40,60}$ Athletic trainers in the athletics model work the most hours out of all three models. ${ }^{14}$ Quality improvement is difficult to achieve when the administrators do not understand the difference between care and coverage. ${ }^{16}$ The athletics model places an undocumented emphasis on coverage of athletic events (practices, strength/conditioning sessions, and/or competition). Athletic trainers in the athletics model spend hours of the work day away from the clinic, providing coverage more so than care.

There has been a recent shift in athletic training to the medical model. This model is also known as the "patient-centered" model. ${ }^{17}$ The medical model can increase coordination of care provided to athletes, which would allow for a higher quality of care. ${ }^{15,17}$ The medical model puts athletic trainers in a position to work for an individual who will always put the medical needs of the athletes first. As a result of increased coordination and an enhanced focus on medicine, the long hours will be shortened, and the focus will change from coverage to care, as the National Athletic Training Association (NATA) recommends. ${ }^{15,18}$ The medical model places an undocumented emphasis on patient care. The athletic trainers spend work hours in the clinic, providing treatment, thoroughly documenting, continuing education, and collaborating with other healthcare professionals. The medical model fosters an environment for continued QI for the patients. 
The workload for athletic trainers in the college/university setting is gradually increasing. ${ }^{40,41}$ Increases in participation time for each team equates to more exposures for injury. ${ }^{42}$ Unfortunately, the athletic trainer to athlete ratio has not decreased. In 2014, in South Carolina, there was an athletic trainer-athlete ratio of 1:87 at all collegiate levels. ${ }^{43}$ Powell and his colleagues ${ }^{42}$ studied 10 NCAA division I schools, in the 2000-2001 and 2001-2002 academic school years. There were 34,269 injuries that required 428,438 treatments in that time frame. Based on the study population, there was 276 full time equivalent athletic trainers to provide those treatments. That's 1625 treatments per athletic trainer in a 2-year span. ${ }^{42}$

The position responsibilities for athletic trainer are so extensive that it becomes difficult to complete all tasks. ${ }^{15}$ Most college/university athletic trainer's response to the size of staff being adequate to fulfill all duties would respond "no". In a study by Mazerolle et al., ${ }^{60} 78 \%$ responded "no". An athletic trainer in the college/university setting is typically responsible for at least 3 teams (90+ athletes) throughout the academic year. ${ }^{60}$ Quality of care has improved in nursing, but based on the athletic arena, healthcare improvement in the athletic training field is slow. Some of this is based on the models of organizational infrastructure incorporated with the athletics model used more than the academic and medical models.

Athletic training services have been under studied and poorly understood from a quality perceptive. $^{2}$ Athletic training departments in the collegiate setting are not staffed well enough to provide the thorough and comprehensive care to all student-athletes. ${ }^{19}$ As a result of the shortage, low-profile sports were less satisfied with the athletic training services they received when compared to high-profile sports at the same institution. ${ }^{19}$ The organizational models of the colleges and universities can have an impact on the athletic trainer to athlete ratio. The organizational models can also affect the priorities (coverage versus care) of the athletic trainers 
working for the colleges and universities. Based on the organizational structures used in the athletic training field the following research questions are asked:

1. Which organizational models are currently being used in NCAA Division I Institutions?

2. Has there been an emphasis placed on quality of patient care in the medical model when compared to the athletic and academic models?

3. What is the hourly break down of the tasks being completed by the athletic trainers during their work day? (practice/game coverage, treatment/rehabilitation, documentation, administrative duties)

Experimental Hypotheses

1. There will be more athletic trainers practicing within the athletics model than the other two models. (academic, athletics, medical)

2. There will be more athletic trainers in the medical model in the high-quality care category than the other two models.

3. There will be more athletic trainers in the athletics model in the low-quality care category than the other two models.

4. There will be more athletic trainers in the athletics model in the high-coverage category than the other two models.

5. There will be more athletic trainers in the medical model in the high-care category than the other two models.

Assumptions

1. Participants will answer the survey items honestly and to the best of their ability.

2. The survey is valid and reliable.

3. Participants will submit the survey completed in its entirety.

\section{Delimitations}

1. This study will use a random sample of athletic trainers in the collegiate setting provided through the NATA Research Survey Service and cannot be generalized beyond the athletic training population.

2. The results of this study cannot be generalized to NCAA Division II or III institutions, as only Division I institutions will be used. 


\section{Operational Definitions}

1. Academic Model - Clinical athletic trainers and athletic training educators are part of the athletic training education program. Practitioners serve dual roles, balancing teaching and clinical responsibilities. ${ }^{14}$

2. Athletics Model - The athletic training staff is a part of the athletic department and the head athletic trainer reports to the athletics director. ${ }^{14}$

3. Athletic Training Coverage- The physical presence of an athletic trainer at practices or events for emergency medical care and injury evaluation.

4. Medical Model - The athletic training staff is aligned with campus health services, and the head athletic trainer reports to another health care professional, such as the team's medical director or physician. ${ }^{14}$

5. Organizational Infrastructure - The hierarchy of staff within a department. This includes clinical staff, supervisors, administrators, and where the funding, budget, and salary for the department comes from. ${ }^{14}$

6. Patient Care- Clinical management of injuries/illnesses which includes: recognition, evaluation, referral, treatment, rehabilitation, return to play determination, and documentation. ${ }^{61}$

7. Patient-Centered Care - The delivery of healthcare services that are focused on the individual patient's needs and concerns. ${ }^{46}$

8. Quality Improvement (QI) - A healthcare concept that ensures patients receive highquality and affordable care. ${ }^{2}$

9. Quality of care - Doing the right thing, at the right time, in the right way, for the right person and having the best possible results. ${ }^{7}$

10. System of Care - The setting in which care is actually delivered. ${ }^{5}$

\section{Limitations}

1. Only using athletic trainers in a specific division of one workplace setting of the profession.

2. The questionnaire used is not a validated questionnaire.

3. The questions on the questionnaire may be misunderstood.

4. The participants will not be taking the questionnaire in a controlled environment. 
5. The busy schedule of the participants may affect their ability to complete the questionnaire.

6. The participants answer the questions in a way they think are the correct answers, rather than answering truthfully.

Significance of Study

There is a need for higher quality healthcare in the college/university setting. There are several barriers to QI in that setting. The models of organizational infrastructure can create and/or alleviate barriers to QI in athletic training. Athletic healthcare has been slow to adopt the medical model. There is a need for schools to change to the medical model for QI. A lack of literature advocating for the medical model and the QI that the model can promise is potentially the reason no sweeping changes have been made to date.

This study will be the first to examine the three models of athletic healthcare from a QI standpoint. The evaluation of quality will be used by administration and athletic training departments to make improvements to the staff and the quality of care provided to student athletes. After the results have been compiled, the goal is to educate athletic trainers, athletic department administrators, team physicians, and college/university health services centers about the benefits and barriers to the organizational models as it relates to quality of patient care in the athletic training profession. The quality of healthcare provided by athletic trainers will improve through organizational changes. With the results of this study athletic trainers can provide a higher quality of healthcare to athletes, earn higher wages, increase staff size and work hours that are less demanding. A secondary goal of this study is to educate administrators on the difference between coverage and care as it relates to the athletic training profession at the college/university setting. The results can be published in academic journals and presented at national conferences 
through the NCAA and NATA regarding the organization of sports medicine staffs in the member institutions. 


\section{APPENDIX B \\ LITERATURE REVIEW}

Introduction

Healthcare professionals are always striving to provide the best possible care to their patients. There can be barriers to accomplishing quality care and there can be environments that quality care thrives in. Healthcare professionals also know that patients can view quality care in many ways. It is the responsibility of the provider to tailor the care to the patients' needs and wants.

To objectively measure quality in healthcare, there have been patient questionnaires and provider questionnaires constructed to establish what is working and not working well in the system of care. These objective measures are a form of quality improvement (QI). Healthcare organizations that foster a culture of constant QI are known to provide the best quality of healthcare.

Quality improvement is universal across all healthcare disciplines. There are many publications regarding QI in nursing and physical therapy. ${ }^{9-13,34-36,47,48,50,51,54,55,57,62-72} \mathrm{~A}$ healthcare profession that has not closely examined the QI initiatives is athletic training. The current practice of athletic training makes it difficult to objectively measure patient outcomes and patient satisfaction. With organizational infrastructure, and administrative changes, the profession of athletic training in the collegiate setting could align the profession to follow along with nursing and physical therapy from a QI perceptive.

The following review of literature will define quality of care and quality improvement in healthcare. The professions of nursing and physical therapy will be examined from a quality of care perceptive. The athletic training profession will also be examined from a quality of care and 
organizational infrastructure preceptive. The aim of the review is to connect the organizational infrastructure of collegiate athletic trainers to the quality of care provided to the student-athletes. Quality of Care

It is the ethical responsibility of every healthcare professional, no matter the field, to provide the best possible care to every patient. ${ }^{1}$ However, what determines quality healthcare is widely variable in the literature, in turn making it difficult to measure. ${ }^{3}$ Steffen $^{72}$ viewed the word "quality" as implying preference. Quality patient care is described by the US Agency for Healthcare Research and Quality as "doing the right thing, at the right time, in the right way, for the right person- and having the best possible outcome". ${ }^{7}$ Patient care can be viewed in many ways. First, each patient has an individual perspective of the ideal care they want to receive from healthcare professionals. Second, Campbell et al. ${ }^{4}$ explained that patient care is not defined by outcomes or the structure of the staff. Patient outcomes are a result of care. The structure of a healthcare staff is the vehicle of delivering the care to the patients. ${ }^{2,4,74}$ Quality in health services increase the chance of receiving a desirable outcome at the population and the individual levels. ${ }^{1,}$ ${ }^{4}$ The use of evidence-based practice also plays a role in achieving desirable outcomes for patients. ${ }^{4}$ Effective clinical care occurs when evidence-based practice is effectively applied. ${ }^{4}$ Effectiveness and access are two components to quality care. Effectiveness can be divided into two parts, clinical effectiveness and effectiveness of interpersonal care. ${ }^{4}$ Involving the patient in the decision-making process, and communication between healthcare provider and patient can result in quality care. This is known at patient-centered care. ${ }^{62,75}$ The patients want a healthcare provider who will communicate with respect, being able to acknowledge the patients wants, needs, beliefs, and preferences. ${ }^{63,76}$ Overall, effective 
communication between clinician and patient can lead to a better patient-provider relationship. This relationship has been known to affect quality of care and outcomes. ${ }^{77}$

The organizational structure of healthcare does not only consist of the staff and personnel. Also included in the structure are equipment, facilities, hours of operation, and appointment booking system. ${ }^{4}$ All of the factors of organizational structure provide the patient with access to healthcare, but on the other hand, do not always guarantee the care will be high in quality. ${ }^{4}$ The process of delivering healthcare is the interaction between the consumer (patient) and the healthcare system. ${ }^{4}$ The process can include clinical interventions and interpersonal interactions. ${ }^{4}$ The structure of the system and the process of care all affect patient outcomes. ${ }^{4} \mathrm{~A}$ safe facility and the necessary equipment should be provided by the structure. ${ }^{4,47}$ Process is defined by technical skills and if they were performed correctly., ${ }^{43,78}$ Similar to Campbell et al. ${ }^{4}$, McKenna et al.$^{79}$ used nurses and patients to identify three constructs of quality of care in nursing (resources, processes, and outcomes). Resources for nurses would include the size of the staff, the patient to nurse ratio, and financial and physical resources available to the nurse. ${ }^{79}$ Processes include the practice of nursing, the care standards and the interpersonal skills of the individual nurses. ${ }^{79}$ The outcomes construct is focused on the patient. Within the outcomes construct would be patient comfort, happiness, feeling informed, and satisfaction ${ }^{79}$ However, not all outcomes and definitions of care can be generalizable to the public. The patient has an individual meaning of quality care and thus ideal outcomes. ${ }^{4}$ Patients want access to friendly and communicative healthcare professionals. ${ }^{4}$ Patients expect healthcare to be safe, effective, patient centered, timely, efficient, and equitable ${ }^{80}$ Supervisors and patients often do not have the same perspective of quality care. Supervisors often have a perception of care related to cost effectiveness. ${ }^{4}$ 
Appropriate staffing and safe facilities/equipment were identified as factors of quality care. ${ }^{47,48}$ The amount of time that staff members spend with patients and listen to patients has also been identified as a factor. ${ }^{49,50}$ The selection of a treatment was less significant compared to how the treatment was delivered to the patient. ${ }^{64}$

There is a disconnect from what healthcare providers view as quality care and what patients view as quality care. Nurses and patients have demonstrated different characteristics for what they respectively define as quality care provided by a nurse. ${ }^{10,65}$ Furthermore, quality can be viewed from the perspective of insurance companies and policy makers. Bringing together all three stakeholders of healthcare (patient, clinician, payer), and merging their view of quality care can fill the gaps in overall increase outcomes. Figure B1 depicts the breakdown of views from all three parties. ${ }^{66}$ The patient wants to receive information about the care they are consuming, and they want medicine that will prevent further health issues. From the clinician perspective, professionalism, scientific advancement, and autonomy are important. Finally, from the perspective of the payer or policy maker, they want patients to have access to cost effective treatment. 66

Goldenberg $^{81}$ suggested that quality of care does not have a definitive description in the literature. She argues that the current definitions of quality and care do not thoroughly explain what quality healthcare looks like. ${ }^{81}$ After thoroughly evaluating several descriptions of quality of care, she proposed her own description, which allows organizations to create their own meaning of quality. Goldenberg ${ }^{81}$ described quality of care as "... refers to the attributes of a health care service that are taken by the relevant stakeholders to be important enough to be measured and promoted within an organization." 


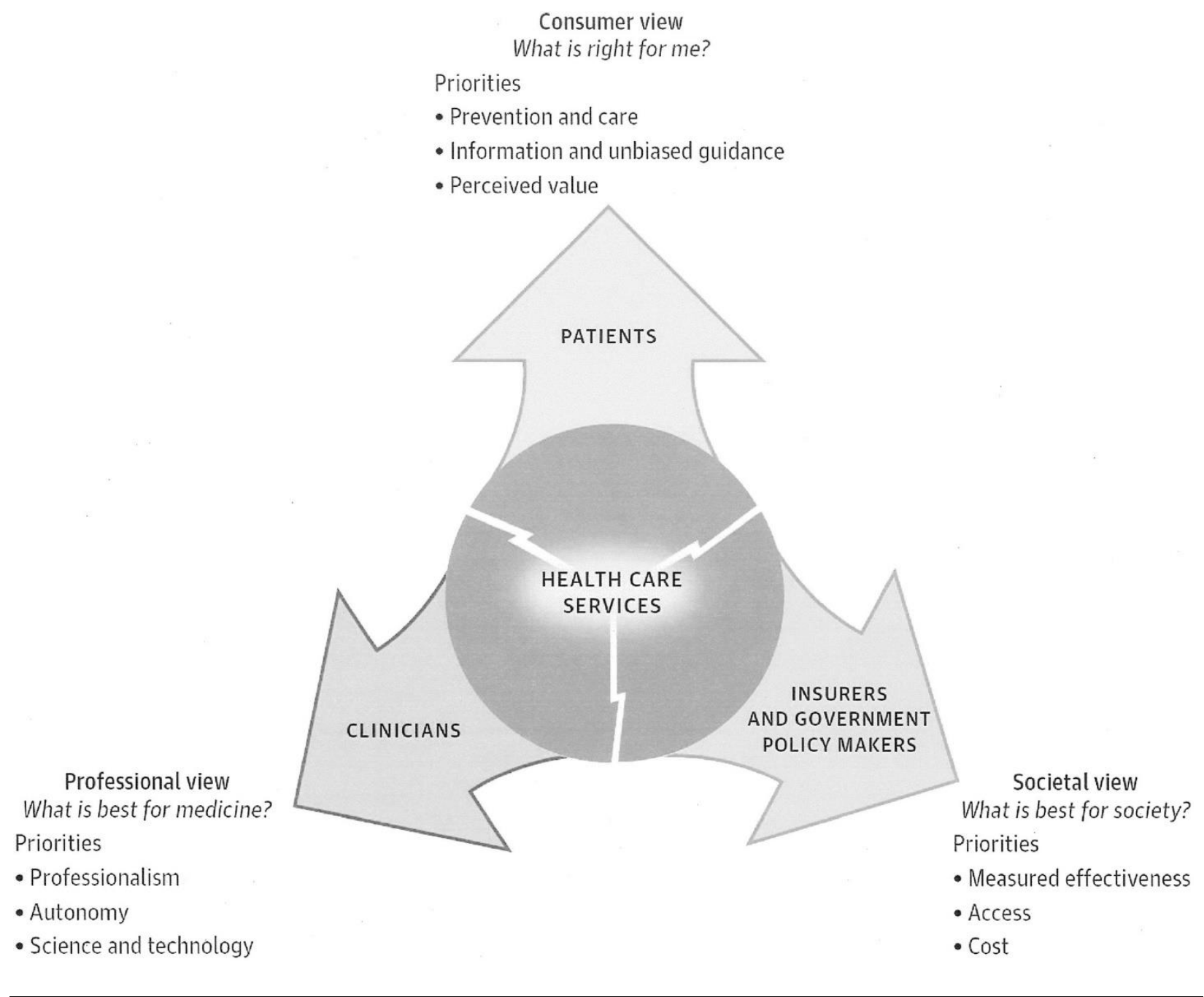

Quality Improvement (QI)

Quality Improvement (QI) in healthcare has been described as "the combined and unceasing efforts of everyone, healthcare professionals, patients and their families, researchers, payers, planners and educators to make the changes that will lead to better patient outcomes (health), better system performance (care) and better professional development (learning)" ${ }^{5}$ The Committee on Quality of Health Care in America released a report regarding the quality of healthcare in the United States.$^{82}$ The report exploited a significant gap between average medical 
care and the best possible care.$^{82}$ If outcomes are measured, practitioners will respond by improving their "performances". ${ }^{83}$ Thus, the measure of outcomes is a form of QI.

It is possible to have structural or cultural barriers to providing quality care to patients. ${ }^{51}$ The culture of the workplace is responsible for the values the employees hold and how things are judged and understood as a community of employees. ${ }^{51}$ Improving the quality of healthcare needs to come as a wide spread change of structure, function, and culture of the organization. ${ }^{51 \text {, }}$ 39, 84, 85 To make these changes, quality improvement (QI) should be adopted. Cultural change needs to occur along with the reorganization of staff and management to provide a culture where quality care is the top priority. ${ }^{39}$ It should be noted that change and improvement are not mutually exclusive. ${ }^{5}$

Quality improvement initiatives are ways to guide clinicians, educators, and researchers to continuously improve the quality of care in respective fields of practice. ${ }^{2}$ Organizations that have a higher commitment to QI experience lower turnover of staff. ${ }^{37}$ The organizations with a high commitment to QI have administrators and senior level staff who were fully committed to the improvement of care. ${ }^{37,86,87}$ For the lower level staff who work in a QI culture, this has been a key component to the functioning of the healthcare system. ${ }^{37}$ Quality improvement is a way for organizations and healthcare professionals to work smarter and make jobs easier. ${ }^{37}$ Barriers such as budget cuts can be easily overcome in a culture of QI. ${ }^{37}$ The greatest barrier to creating a QI culture is leadership in the organization. ${ }^{38}$ Table B1 highlights the five keys to creating a culture of QI. ${ }^{37}$ For QI to be successful in an organization, the leadership of the organization need to be committed to the initiative. ${ }^{37}$ The mission of the organization and the goals set by the organization need to align with the QI initiative. ${ }^{37}$ The organization has to have a strong base of evidence-based practice, performance evaluation, and access to new research data to be 
successful. ${ }^{37}$ The organization needs to hold the employees accountable to create a culture of QI from top to bottom. ${ }^{37}$

Table B1. Five Keys to Creating a Culture of Quality Improvement ${ }^{37}$

1. Leadership and staff are committed to QI

2. The organization values innovation and incorporates QI into the mission and goals

3. Organizations with experience in evidence-based practice and performance management are more likely to succeed

4. Employees are held accountable for outcomes that makes the organization cognizant of QI.

5. Organizations with QI teams and access to new data are more likely to create a culture of QI.

Quality improvement is achieved systematically. ${ }^{88}$ Varkey et al ${ }^{88}$ wrote about the

Continuous Quality Improvement model with an emphasis on the view of healthcare as a process that focuses on the system rather than the individual. There is an approach to healthcare improvement known as "plan-do-study-act" ${ }^{88}$ The plan step of this approach requires an objective, a prediction, and a plan to carry out a test. ${ }^{88}$ The do step requires a test of the prediction. ${ }^{88}$ The do step needs to be documented to observe changes. ${ }^{88}$ The study step of the approach compiles the results of the previous step. ${ }^{88}$ The final step (act) determines what changes need to be made to reach the objective. ${ }^{88}$ Organizations that have a high commitment to QI were more likely to use "plan-do-study-act" and a range of other QI methods. ${ }^{37}$ Quality of Care in Other Health Professionals

Quality of care in other health professions has been evaluated including nursing and physical therapy. The nursing profession has undergone changes to improve the nurse to patient ratio ${ }^{81}$ It has been found that patient outcomes improve if the nurses are adequately staffed. ${ }^{35,36}$ In physical therapy, patient satisfaction questionnaires are used to change and improve the care 
given by physical therapists. Physical therapists have improved by increasing patient contact time, listening, educating, and evaluating.

Nursing: Despite federal laws and state regulations, the minimum nurse-patient ratio is well below what is recommended. ${ }^{36}$ Adverse events in nursing are directly related to substandard treatment, inadequate monitoring, and delays or failures in treatment. ${ }^{10,36,67}$ Approximately $70 \%$ of nursing homes in the United States are "for-profit" facilities. ${ }^{36}$ These facilities have lower staffing and more violations compared to "non-profit" nursing homes. ${ }^{36}$ The patient's best interest is placed as a secondary priority in facilities seeking profit. ${ }^{36}$

Aiken et al.$^{68}$ found a relationship between patient satisfaction and the nurse's workload. The less work the individual nurse had, the more satisfied the patient was. ${ }^{68}$ Patient satisfaction reflects the quality of care received. ${ }^{10}$ The size of a nursing staff can affect the patient outcomes and the patient satisfaction. Both outcomes and satisfaction have been identified as factors for quality healthcare. Quality nurses must practice patient-centered care to improve the quality of care deliver to patients. Patient satisfaction surveys have been criticized for effectiveness. ${ }^{10}$ The criticism has sparked an initiative to create more sensitive patient questionnaires about the acceptability, appropriateness, and effectiveness of patient care. ${ }^{10}$ In some ways, there is a disconnect as to what is expected of a health care professional. Patients find that outcomes and reliability of health professionals are important factors of quality care. ${ }^{10,69}$ Nurses view interpersonal relations as the characteristic of a quality nurse. Patients believe competence, knowledge, and technical skills are more important to be a quality nurse.${ }^{10}$ Currie et al.${ }^{10}$ listed nine characteristics of a quality system of care for nurses which can be found in Table B2. For nurses to be successful in delivering quality care, they must work in an organization that places 
nurses in leadership roles, allows nurses autonomy both clinically and professionally, and allows the nurse to professionally develop and grow. ${ }^{10}$

Table B2. Nine Characteristics of a Quality System of Care for Nursing ${ }^{10}$

1. There is an executive nurse on the board of the organization.

2. Management is supportive and participatory in daily tasks of the department.

3. Staff size is adequate for the patient load.

4. Nurses have the ability to create their own working hours.

5. Nurses have professional autonomy.

6. Nurses have specialist advice available to them.

7. There is a strong emphasis on continuing education.

8. There is a competency based clinical ladder (specialization in technical skills).

9. Management development program for nurses. These characteristics are also associated with better patient outcomes. ${ }^{10}$ Mark et al. ${ }^{35}$ noted that hospitals with higher levels of nurse staffing were associated with a reduction in mortality rates. Adding nurses to a hospital that is understaffed resulted in a decrease in mortality rates. ${ }^{35}$ But, adding nurses to a hospital that was already adequately staffed did not change the rate of mortality. ${ }^{35}$ The well-staffed hospitals already had the patients covered well enough and that did not change with more nurses. ${ }^{35}$ But, when more nurses worked with the understaffed hospitals, they were able to better cover the workload and be more diligent with work. ${ }^{35}$ Dang et al. ${ }^{70}$ also made a connection to the size of nursing staff and negative outcomes. Low- and medium-intensity intensive care unit nursing staffs had a higher chance a patient will end up with respiratory or cardiac complications. ${ }^{70}$

Physical Therapy: Patient care in physical therapy has revolved around patient questionnaires. The development of a patient questionnaire highlights the domains of patient care 
in physical therapy. ${ }^{12}$ The use of a patient questionnaire has undergone a change, organizations no longer ask for the opinion of the patients, but rather ask the patients for subjective information regarding their experience with the healthcare services they received. ${ }^{13}$ Goldstein et al. ${ }^{12}$ created a questionnaire which highlighted the following domains: treatment, privacy, convenience of appointment time, cost, billing, ease of scheduling, wait time, courteous staff, physical therapist is courteous, and overall satisfaction. Patients of physical therapy view the quality of care through a lens of access and interpersonal relations. ${ }^{12}$ Physical therapists use patient satisfaction questionnaires to evaluate the quality of the care provided and the facilities where the care is delivered. ${ }^{12}$ In theory, as a result of patient satisfaction questionnaires, changes could be made to the manner in which care is delivered and the quality of facility where the care is delivered.

According to Schlote et al. ${ }^{13}$ consumers of physical therapy experience four categories of the service received. The categories include receiving necessary care, receiving care quickly, how well the physical therapists communicate, and customer service. ${ }^{13}$ All four of the domains listed by Goldstein et al. ${ }^{12}$ can fit within a category listed by Schlote et al. ${ }^{13}$ The patients want care that will make them better and is easy to access. ${ }^{12,13}$ The patients want to be able to communicate with the staff and physical therapists effectively and they want a hassle-free experience with billing and scheduling. ${ }^{12,13}$

Arnetz et al. ${ }^{54}$ completed a study about patient satisfaction with physical therapy services in patients with chronic illnesses. It was purposed that patients who infrequently receive care from a physical therapist do not fully understand the service recieved. ${ }^{54}$ Patients with chronic illness are experienced enough to have a different perspective of the service. ${ }^{54}$ Patients with chronic illnesses were more satisfied with the quality of physical therapy services when actively involved in the establishment of treatment goals.${ }^{54}$ The treatment outcomes also were improved 
compared to a control group who were not involved in goal setting. ${ }^{54}$ This is an example of how a healthcare profession can take an active role in improving the quality of care delivered to the patients.

Resnik et al. ${ }^{11}$ examined the differences between expert and novice physical therapists. Experienced physical therapists spend more time with patients providing hands-on care, seeking information, evaluating and educating the patient. ${ }^{11,71}$ Expert physical therapists were noted as having a patient-centered approach to patient care. ${ }^{11}$ The expert physical therapist educated the patient to the extent that the patient was empowered and self-reliant. ${ }^{11,72}$ Physical therapists were also able to rely on colleagues for support and consultation when needed. ${ }^{11}$ Other studies have focused on involving the patient in the medical decision making and goal setting to improve outcomes and therefore improve the quality of the care delivered by physical therapists. ${ }^{54-57}$ Quality Care in Athletic Training

There is a gap in the literature in describing quality of care in the athletic training setting. The quality of care that athletic trainers (AT) provide is poorly understood from value, quality and cost perceptives. ${ }^{2}$ Because of this, quality of care in athletic training has been studied at the individual level ${ }^{20,25,69,89}$ but not at the organizational level. Further, athletic trainers lack formal training to evaluate the systems of care and to initiate QI initiatives. ${ }^{2}$ Improving the systems of care ATs work in has the ability to improve the quality of care delivered and improve patient outcomes. ${ }^{2,90}$ Quality improvement for ATs can be achieved through diligent patient care documentation and the use of evidence-based practice. ${ }^{2}$ Objective measures of outcomes and uniform documentation across the profession of athletic training can create an environment for QI. $^{2}$ 
DeSimone ${ }^{25}$ studied the athletic trainer's self-perspective of the quality of care provided to student athletes. There were no significant differences in experience, tenure, gender, NCAA division, or the number of athletes the AT is responsible for. ${ }^{25}$ In quality of care, athletic trainers are concerned about the patients and other interactions on a day to day basis ${ }^{69}$ There is an understanding that each patient deserves attention no matter the severity of the injury or how many patients are waiting in the athletic training room. ${ }^{69}$ No one patient is more important than the other. ${ }^{67}$ Unruh et al. ${ }^{19}$ studied the satisfaction of college student athletes. Student athletes who participated in low-profile sports felt the athletic trainer spent less time with them and thus were less satisfied with the care delivered by the athletic trainer. ${ }^{19}$ Similarly, Porterfield ${ }^{20}$ also studied college student athlete's satisfaction with the athletic trainer. There was a significant difference in satisfaction among different sports and different NCAA divisions, but no difference between genders. ${ }^{20}$ In addition to attention, communication was noted as a necessary skill for a quality AT. ${ }^{69}$ Athletic trainer's communication with student athletes, colleagues, other healthcare professionals, coaches, and athletic administrators are all necessary in the care of the student athlete. ${ }^{16,17,46,69,91,92}$ Quality ATs share knowledge and are always seeking opportunities to expand and broaden knowledge. ${ }^{69}$ Athletic trainers should be able to admit when something is outside the knowledge base available and be able to work with other healthcare professionals to bring that ability to the patient. ${ }^{69}$ However, from the patients perceptive, quality ATs commit time to the profession by availability to patients. ${ }^{21,69}$

Athletic trainers have unique responsibilities within the healthcare field. A collegiate athletic trainer is responsible for the healthcare of all athletes on the rosters of a team or several teams depending on the institution. The National Athletic Trainers Association (NATA) released a document highlighting the expected services an athletic trainer must provide to deliver quality 
care to their patients. ${ }^{89}$ The document lists five domains of the profession, injury and illness prevention and wellness protection, clinical evaluation and diagnosis, immediate and emergency care, treatment and rehabilitation, and organizational and professional health and well-being. ${ }^{93}$ Despite guidelines being provided by the professional organization in regard to care, many institutions require athletic trainers to be physically present at all team practices and to travel with teams to away contests. Thus, connecting care with coverage, which may not have been the original intent of the document.

Athletic trainers are often the first responders to athletic injuries and illness because of the role in practice and event coverage. The NATA released a publication in 2007 describing the appropriate coverage of intercollegiate athletics. ${ }^{30}$ Described within the publication is the definition of appropriate responsibilities of the athletic trainer outside the role of practice and event coverage. (See Table B3) Despite the recommendations, AT's still appear to spend more time with coverage. ${ }^{30}$ In addition to event and practice coverage, athletic trainers often have responsibilities such as injury prevention programs, treatment and rehabilitation of injuries and illnesses, return to play decision making, nutrition and psychosocial treatment and referral, documentation, and continuing education. ${ }^{30}$

Eight of the 9 responsibilities listed in Table B3 involve patient care. Despite the number of responsibilities an athletic trainer must fulfill, the administration demands that the athletic trainer spend hours of the day providing event and practice coverage. There is a disproportionate amount of time in an athletic trainer's day being spent on coverage when the focus should be on patient care. 
Table B3. Appropriate Responsibilities of the Athletic Trainer. ${ }^{30}$

1. Emergency care and event coverage

2. Determination of athlete's readiness to return to participation

3. Risk management and injury prevention

4. Recognition, evaluation and immediate treatment of athletic injuries and illnesses

5. Rehabilitation and reconditioning of athletic injuries

6. Psychosocial intervention and referral

7. Nutritional aspects of injuries

8. Healthcare administration

9. Professional development to maintain and improve knowledge and skills

At the Division I level of the National Collegiate Athletic Association (NCAA), sports

medicine staffs that cover football often spend up to $80 \%$ of the calendar year providing practice and event coverage for that team. ${ }^{45}$ Football is also a sport that requires many ATs to travel with the team to away events. At the Football Bowl Series (FBS) level of the NCAA DI, football teams travel for $15.7 \pm 5.5$ days of the year. ${ }^{45}$ On those trips, the team will take $4.1 \pm 1.4$ ATs for a regular season game and $4.4 \pm 1.5$ ATs for a post season game. ${ }^{45}$ The average staff size in FBS is nine full time ATs. ${ }^{44}$ Only one third of FBS schools have enough full time ATs to cover football. ${ }^{45}$ In all of DI athletics in the NCAA, ATs are responsible for at least three athletic teams and 90 or more student-athletes. ${ }^{41}$ Most school's employ only seven full time ATs and sponsor between 20 and 28 sports. ${ }^{41}$ Mazerolle et al. ${ }^{41}$ evaluated the DI setting in regard to the size of staff and whether the staff was large enough to fulfill all the responsibilities of a program at that level. Seventy-eight percent responded with "no". Athletic trainers work up to 80 hours a week during a sport season to provide medical care, traveling with the team, and fulfilling administrative duties. ${ }^{14,28}$ 
The NCAA is now allowing football and men's and women's basketball programs to require athletes to participate in up to eight hours a week of team activities in the summer months. ${ }^{28}$ According to the NATA recommendations, those activities must be covered by an AT. ${ }^{30}$ Also, more exposure (practices and other team activities) equates to more injuries. ${ }^{16,28}$ Supervisors have the ability to support staff members in the control over work schedules. ${ }^{28}$ Implementing job sharing is an example of supervisor support that could reduce the number of hours an AT works during the summer months. Using one centralized athletic training facility in the summer for all sports can reduce the number of ATs needed to staff the facilities..$^{29,91}$

Athletic trainers have come to expect that the demands of the job are not easy. Time demands such as being on call for 24 hours a day, 7 days a week, working most evenings, and having work interfere with family obligations. ${ }^{14,91,94}$ Coaches and athletic administration have unrealistic expectations and a lack of appreciation..${ }^{94}$ Eason et al. ${ }^{27}$ described what ATs can expect from working in the collegiate setting: long, irregular hours, long road trips, pressure to win, supervision of student ATs, long seasons, last-minute schedule changes, and supervisors who may not be medical professionals. All of those can be barriers for the athletic trainer in providing quality healthcare to the student-athletes.

Supervisors of athletic trainers in the collegiate setting have the ability to control hours worked through policies and procedures. ${ }^{91,95}$ Operation policies that can be adjusted include hours of operation, traditional versus non-traditional season coverage, travel expectations, and schedule changes of practices and events with appropriate advanced notice. ${ }^{15,91}$ The AT and supervisor should make all athletic department staff, administrators, coaches, and athletes aware of the operational policies in place for the department. ${ }^{91}$ Supervisors can assess the workload of all ATs on staff and encourage job sharing. ${ }^{91}$ Job sharing, as described above, is when other ATs 
cover events when the primary AT is not available for any reason. ${ }^{15,91}$ The sports medicine department should provide employees with time and compensation for staff members to attend professional conferences for continuing education. ${ }^{91}$ The supervisor should also advocate to the athletic administration for higher salaries that correlate to job responsibilities and for more fulltime staff members to reduce to work load of the current staff. ${ }^{91}$

For ATs, quality medical care must be the top priority in times of conflict with coaches or athletic administrators. ${ }^{46}$ Coaches should never be a supervisor to the member of the sports medicine team, nor should they be involved in the appointment or employment of sports medicine staff members. ${ }^{46}$ Schools should have a line of unchallengeable authority for the team physician and athletic trainers to make medical decisions without input from coaches or athletic administrators. ${ }^{46}$ At the collegiate level there should be a healthcare professional (team physician or head AT) as a senior level athletic administrator. ${ }^{46}$ This person can prioritize the health, safety, and welfare of all athletes as well as have an input in budget, risk management, institutional liability, quality assurance, and athlete satisfaction. ${ }^{46}$ Models of Organization in Athletic Training

There are currently three models of organizational infrastructure being employed within the NCAA Division One. The academic model employs athletic trainers through an academic school or college and is often a part of the athletic training education program..${ }^{15}$ The athletic model employs athletic trainers through the athletics department. ${ }^{14}$ All funds for the salaries and budget for the athletic trainers come from the athletics department. ${ }^{14}$ The final model of organization is the medical model. Athletic trainers in the medical model are employed through the school's student health services. ${ }^{14}$ The athletic department then makes a contract with student health services to use the services of the athletic trainers for the student athletes within the 
athletic department. ${ }^{14}$ Mazerolle and colleagues ${ }^{14-16}$ conducted a three-part study examining all three models of organizational infrastructure. To date, these are the only studies to examine the models. The three studies view the models from a quality of life and work-life balance aspect. ${ }^{14-}$ 16

Academic model: Athletic trainers in the academic model are employed under an academic dean or chair of a school. ${ }^{15}$ Athletic trainers in the academic model serve multiple or dual roles, which can cause role strain. ${ }^{14,15}$ They often serve as clinical ATs and AT educators within the athletic training education program. ${ }^{14}$ Athletic trainers within the academic model often feel less support from coworkers and direct supervisor. ${ }^{14}$ To date, Eason et al. ${ }^{15}$ is the only study available to examine the academic model of organization for college athletic trainers.

Dual-role athletic trainers are often found in the secondary school setting. ${ }^{96}$ The athletic trainer may be hired as a physical education teacher with added responsibilities as an athletic trainer. The dual role athletic trainer is responsible for teaching courses, grading, curriculum writing, student-athlete care, practice preparation, and practice and event coverage. ${ }^{96}$ The dualrole athletic trainers in the secondary school setting identified four barriers to successfully performing responsibilities: time-related issues, role-relationship, support and appreciation, and role clarification/negotiation. ${ }^{96}$ These barriers to success as an athletic trainer can be generalized to the collegiate setting, especially to the athletic trainers employed within the academic model.

Athletics model: Most schools follow the athletics model of organization. ${ }^{14}$ In the athletics model, the sports medicine department is a part of the athletic department. ${ }^{14}$ The head AT reports to an athletic director. In the athletics model of organization, the athletic administrators have control over the budget and policies of the sports medicine department. ${ }^{16,17}$ Capital items such as salaries, equipment, supplies, medical expenses, and insurance all come out 
of the athletic department budget. ${ }^{16}$ The quality of care to the patients is limited to the knowledge of the one AT who is assigned to cover that particular sport. ${ }^{17}$ In some cases, the AT is forced to operate in relative isolation from any other healthcare professional. ${ }^{17}$

Being housed within the athletic department can create conflicts over medical treatment plans from the coaches or the athletic administrators. ${ }^{14,16}$ The ATs who are trying to provide the proper medical care to the athletes can be pressured by the wants and needs of the athletic department staff and coaches to return the athlete to play as soon as possible. ${ }^{16} \mathrm{~A}$ hierarchy that coaches have power and influence over the ATs should be eliminated. ${ }^{14}$ This could create a hostile work environment where the values of the AT are being challenged. ${ }^{14,16}$ There have been some cases where ATs have been terminated over disagreements with medical treatment plans. ${ }^{16}$ Athletic trainers in the athletics model feel they have less support from administration compared to the other models of organization. ${ }^{14}$ Athletic trainers in the athletics model are less satisfied with compensation than ATs in the other two models. ${ }^{14}$ The ATs in the athletics model also work more hours than the ATs in the other models. ${ }^{14}$ Often times, ATs in the athletics model are asked to serve multiple administrative roles such as inventory control, physician clinic coordination, or insurance claims. ${ }^{16}$ Athletic trainers serving in multiple roles find it difficult to complete all tasks in a timely manner. ${ }^{16}$ Because of this role strain, the quality of healthcare delivered by ATs can suffer. ${ }^{16}$ The athletic department often do not understand the difference between AT coverage and AT care. ${ }^{16}$ This misunderstanding can create expectations that will cause the level of healthcare to plummet. ${ }^{16}$ Goodman et al. ${ }^{16}$ examined the benefits and barriers to quality of life within the athletic model. ${ }^{16}$ To date this is the only study available examining the athletics model of organization. 
There are some advantages to working in the athletics model. The ATs feel they have a closer relationship and better communication with athletic department personnel. ${ }^{16}$ Athletic trainers also feel they identify with role more closely in the athletic model. ${ }^{16}$ Some schools have healthcare professionals as athletic directors which can be beneficial. ${ }^{16}$

Medical model: The medical model is also known at the patient-centered model. ${ }^{17}$ This model is managed by medical professionals. The AT staff report directly to the team's medical director or physician. ${ }^{14}$ The medical supervisor is able to limit potential conflicts because of the knowledge of the athletic training profession. ${ }^{15}$ The sports medicine department would operate as an independent clinical unit that employees ATs outside the athletic department. ${ }^{17}$ The department would be a branch of the university's student health services. ${ }^{14,15,17}$ There is a sense of job stability and security for the ATs when the team physician is employed by student health services. ${ }^{15}$ Benefits to the patient-centered model include a wider variety of healthcare providers available to the student-athletes, more ways for the staff to improve skills and receive performance evaluations and budget increases to hire more staff and to raise salaries. ${ }^{15,17}$ The medical model also provides an opportunity for shared patient duties in a collaborative treatment style. Collaboration from the ATs on staff would improve patient care, decrease the number of hours worked, improve the quality of life for the staff, and encourage a referral of patients on the basis of the clinical expertise of the individual AT on the staff. ${ }^{15,17}$ Athletic trainers operating in the medical model work the least number of hours compared to the other two models of organization. ${ }^{14}$ Athletic trainers in the medical model feel most aligned with each other when the patient's best interest is the top priority of the department. ${ }^{15}$ Winning and losing is no longer the main topic of concern which allows the ATs to focus on patient care. ${ }^{15}$ To date, Eason et al. ${ }^{15}$ is the only available study to examine the medical model. 
Summary

Quality healthcare can be interpreted in many ways. It is known that patients value communication and ease of access when they are consumers of healthcare. Quality improvement initiatives are ways to guide clinicians to improve the quality of healthcare delivered to patients. ${ }^{51}$ Organizations with a high commitment to quality improvement have administrators and senior level staff who were fully committed to the improvement of care. ${ }^{51}$ In other healthcare professions (Nursing and physical therapy) staffing levels, competence, and communication have been noted as characteristics of quality healthcare. ${ }^{10,12,13,35}$ The quality of healthcare the athletic trainer provides to patients is an understudied topic. ${ }^{2}$ In some cases, the organizational structure and model used, whether academic, athletics, or medical model employed, dictate the quality of care provided by the athletic trainer. As of now, coverage versus care has not been resolved in the athletic training arena. 
APPENDIX C

ADDITIONAL METHODS

Table C1. Initial Cover Letter to Certified Athletic Trainers

February 12, 2019

Dear Participant,

This letter is a request for you to take part in a research project to assess how the athletic training staffing model a school uses affects the quality of care athletic trainers deliver to student athletes. This project is being conducted by Matthew Ferreira, ATC, CSCS in the College of Physical Activity and Sport Science at West Virginia University with supervision from Dr. Michelle Sandrey, $\mathrm{PhD}$, ATC, program director of the Graduate Athletic Training Program. This project is a partial requirement for a Master Degree in Athletic Training. Your participation in this project is greatly appreciated and will take approximately 20 minutes to complete the attached questionnaire. You will have 28 days to complete this questionnaire. Please follow the link to the questionnaire:

https://nata.co1.qualtrics.com/jfe/preview/SV_3CSb3x5L4M81yy9?Q_SurveyVersionID=curren t\&Q_CHL=preview

Your involvement in this research will be kept confidential as legally possible. All data will be reported in the aggregate. You must be 18 years of age or older to participate. I will not ask any information that should lead back to your identity as a participant. Your participation is completely voluntary. You may skip any question that you do not wish to answer and you may discontinue at any time. West Virginia University's Institutional Review Board acknowledgement of this project is on file.

I hope that you will participate in this research project, as it could be beneficial in understanding the impact of models of organization athletic trainers are employed in and the effect on quality of care. Thank you very much for your time. Should you have any questions about this letter or the research project, please feel free to contact Matthew Ferreira at (978)-479-6272 or by e-mail at mf0055@mix.wvu.edu. You may also contact Dr. Michelle Sandrey, Principal Investigator and Graduate Athletic Training Program Director at West Virginia University, at (304) 293-0870 or at msandrey@mail.wvu.edu.

Sincerely,

Matthew M. Ferreira, ATC, CSCS 
February 20, 2019

Greetings again,

This is a reminder that the survey on the organizational models of athletic training staffs and the quality of care must be completed by March 5,2019 for participation in the study. This is an excellent opportunity to take part in this research study where information may be lacking. For those of you who have already submitted your response or are in the process, I apologize for the interruption and thank you for your participation. For those of you who no longer have the information, please use the link provided below to complete this questionnaire.

This project is being conducted by Matthew Ferreira, ATC, CSCS in the College of Physical Activity and Sport Science at West Virginia University with supervision from Dr. Michelle Sandrey, $\mathrm{PhD}$, ATC, program director of the Graduate Athletic Training Program. This project is a partial requirement for a Master Degree in Athletic Training. Your participation in this project is greatly appreciated and will take approximately 20 minutes to complete the attached questionnaire. Please follow the link to the questionnaire:

https://nata.co1.qualtrics.com/jfe/preview/SV_3CSb3x5L4M81yy9?Q_SurveyVersionID=curren t\&Q_CHL=preview

Your involvement in this research will be kept confidential as legally possible. All data will be reported in the aggregate. You must be 18 years of age or older to participate. I will not ask any information that should lead back to your identity as a participant. Your participation is completely voluntary. You may skip any question that you do not wish to answer and you may discontinue at any time. West Virginia University's Institutional Review Board acknowledgement of this project is on file.

I hope that you will participate in this research project, as it could be beneficial in understanding the impact of models of organization athletic trainers are employed in and its effect on quality of care. Thank you very much for your time. Should you have any questions about this letter or the research project, please feel free to contact Matthew Ferreira at (978)-479-6272 or by e-mail at mf0055@mix.wvu.edu. You may also contact Dr. Michelle Sandrey, Principal Investigator and Graduate Athletic Training Program Director at West Virginia University, at (304) 293-0870 or at msandrey@ mail.wvu.edu.

Sincerely,

Matthew M. Ferreira, ATC, CSCS 
February 26, 2019

Greetings again,

This is a reminder that the survey on the organizational models of athletic training staffs and the quality of care must be completed by March 5,2019 for participation in the study. This is an excellent opportunity to take part in this research study where information may be lacking. For those of you who have already submitted your response or are in the process, I apologize for the interruption and thank you for your participation. For those of you who no longer have the information, please use the link provided below to complete this questionnaire.

This project is being conducted by Matthew Ferreira, ATC, CSCS in the College of Physical Activity and Sport Science at West Virginia University with supervision from Dr. Michelle Sandrey, $\mathrm{PhD}$, ATC, program director of the Graduate Athletic Training Program. This project is a partial requirement for a Master Degree in Athletic Training. Your participation in this project is greatly appreciated and will take approximately 20 minutes to complete the attached questionnaire. Please follow the link to the questionnaire:

https://nata.co1.qualtrics.com/jfe/preview/SV_3CSb3x5L4M81yy9?Q_SurveyVersionID=curren t\&Q_CHL=preview

Your involvement in this research will be kept confidential as legally possible. All data will be reported in the aggregate. You must be 18 years of age or older to participate. I will not ask any information that should lead back to your identity as a participant. Your participation is completely voluntary. You may skip any question that you do not wish to answer and you may discontinue at any time. West Virginia University's Institutional Review Board acknowledgement of this project is on file.

I hope that you will participate in this research project, as it could be beneficial in understanding the impact of models of organization athletic trainers are employed in and its effect on quality of care. Thank you very much for your time. Should you have any questions about this letter or the research project, please feel free to contact Matthew Ferreira at (978)-479-6272 or by e-mail at mf0055@mix.wvu.edu. You may also contact Dr. Michelle Sandrey, Principal Investigator and Graduate Athletic Training Program Director at West Virginia University, at (304) 293-0870 or at msandrey@ mail.wvu.edu.

Sincerely,

Matthew M. Ferreira, ATC, CSCS 
Table C4: Questionnaire to Division I Athletic Trainers

1) Are you a BOC certified athletic trainer?
a. Yes
b. No

2) Are you currently employed as a clinical athletic trainer in the collegiate setting?
a. Yes
b. No

3) Which division of the NCAA do you currently work in?
a. Division I
b. Division II
c. Division III

4) Please select the category that best describes the current position you hold.
a. Full-time, clinical staff
b. Full-time, educator only
c. Graduate Assistant
d. Intern
e. Resident
f. Fellow

5) Directions: The statements below refer to aspects of care you provide to student athletes. For each statement, please indicate the response that comes closest to your viewpoint at this time. Possible responses range from strongly disagree to strongly agree.

\begin{tabular}{|l|l|l|l|l|l|}
\hline & \multicolumn{3}{|c|}{ Please answer the follow as best as you can. } \\
\cline { 2 - 5 } & $\begin{array}{l}\text { Strongly } \\
\text { disagree }\end{array}$ & $\begin{array}{l}\text { Somewhat } \\
\text { disagree }\end{array}$ & Neutral & $\begin{array}{l}\text { Somewhat } \\
\text { agree }\end{array}$ & $\begin{array}{l}\text { Strongly } \\
\text { agree }\end{array}$ \\
\hline $\begin{array}{l}\text { I often find that I don't } \\
\text { complete everything I } \\
\text { should in my job. }\end{array}$ & & & & \\
\hline $\begin{array}{l}\text { It is difficult to manage the } \\
\text { athletic training position if } \\
\text { you are too involved with } \\
\text { the patients. }\end{array}$ & & & & & \\
\hline $\begin{array}{l}\text { I seldom have time to try } \\
\text { and understand what the } \\
\text { patients think about our } \\
\text { care. }\end{array}$ & & & & & \\
\hline $\begin{array}{l}\text { I am readily available to the } \\
\text { student athletes for } \\
\text { treatment times. }\end{array}$ & & & & & \\
\hline $\begin{array}{l}\text { I am readily available to } \\
\text { coaches for consultation } \\
\text { about student athletes' } \\
\text { injury/illness }\end{array}$ & & & & & \\
\hline
\end{tabular}


6) Directions: The statements below refer to aspects of care you provide to student athletes. For each statement, please indicate the response that comes closest to your viewpoint at this time. Possible responses range from strongly disagree to strongly agree.

\begin{tabular}{|l|l|l|l|l|l|}
\hline & \multicolumn{3}{|c|}{ Please answer the follow as best as you can. } \\
\cline { 2 - 5 } & $\begin{array}{l}\text { Strongly } \\
\text { disagree }\end{array}$ & $\begin{array}{l}\text { Somewhat } \\
\text { disagree }\end{array}$ & Neutral & $\begin{array}{l}\text { Somewhat } \\
\text { agree }\end{array}$ & $\begin{array}{l}\text { Strongly } \\
\text { agree }\end{array}$ \\
\hline $\begin{array}{l}\text { Providing colleague support } \\
\text { network/mechanisms would } \\
\text { increase the quality of care. }\end{array}$ & & & & & \\
\hline $\begin{array}{l}\text { The patients at work nearly } \\
\text { always receive good care. }\end{array}$ & & & & & \\
\hline $\begin{array}{l}\text { When a student athlete } \\
\text { enters the AT room they do } \\
\text { not wait for more than 10 } \\
\text { minutes for an AT to } \\
\text { complete work with other } \\
\text { athletes before they are } \\
\text { seen. }\end{array}$ & & & & & \\
\hline $\begin{array}{l}\text { I collaborate and consult } \\
\text { with other ATs or other } \\
\text { medical professionals when } \\
\text { I am unsure of an injury. }\end{array}$ & & & & & \\
\hline $\begin{array}{l}\text { As a staff, ways of } \\
\text { improving the care provided } \\
\text { to athletes is discussed. }\end{array}$ & & & & & \\
\hline
\end{tabular}


7) Directions: The statements below refer to aspects of care you provide to student athletes. For each statement, please indicate the response that comes closest to your viewpoint at this time. Possible responses range from strongly disagree to strongly agree.

\begin{tabular}{|l|l|l|l|l|l|}
\hline \multirow{2}{*}{} & \multicolumn{3}{|c|}{ Please answer the follow as best as you can. } \\
\cline { 2 - 5 } & $\begin{array}{l}\text { Strongly } \\
\text { disagree }\end{array}$ & $\begin{array}{l}\text { Somewhat } \\
\text { disagree }\end{array}$ & Neutral & $\begin{array}{l}\text { Somewhat } \\
\text { agree }\end{array}$ & $\begin{array}{l}\text { Strongly } \\
\text { agree }\end{array}$ \\
\hline $\begin{array}{l}\text { My supervisor is able to } \\
\text { manage the department as a } \\
\text { whole team to enable } \\
\text { everyone's needs to be met. }\end{array}$ & & & & & \\
\hline $\begin{array}{l}\text { My supervisor thinks about } \\
\text { how the work in my } \\
\text { department can be } \\
\text { organized to jointly benefit } \\
\text { employees and the } \\
\text { company. }\end{array}$ & & & & & \\
\hline $\begin{array}{l}\text { I can depend on my } \\
\text { supervisor to help me with } \\
\text { schedule conflicts if needed. }\end{array}$ & & & & & \\
\hline $\begin{array}{l}\text { My supervisor is creative in } \\
\text { reallocating job duties to } \\
\text { help my department work } \\
\text { better as a team. }\end{array}$ & & & & & \\
\hline $\begin{array}{l}\text { The division of } \\
\text { responsibility in our } \\
\text { department works well. }\end{array}$ & & & & & \\
\hline
\end{tabular}


8) Directions: The statements below refer to aspects of care you provide to student athletes. For each statement, please indicate the response that comes closest to your viewpoint at this time. Possible responses range from strongly disagree to strongly agree.

\begin{tabular}{|l|l|l|l|l|l|}
\hline & \multicolumn{3}{|c|}{ Please answer the follow as best as you can. } \\
\cline { 2 - 5 } & $\begin{array}{l}\text { Strongly } \\
\text { disagree }\end{array}$ & $\begin{array}{l}\text { Somewhat } \\
\text { disagree }\end{array}$ & Neutral & $\begin{array}{l}\text { Somewhat } \\
\text { agree }\end{array}$ & $\begin{array}{l}\text { Strongly } \\
\text { agree }\end{array}$ \\
\hline $\begin{array}{l}\text { Generally, my co-workers } \\
\text { and I work as a team and } \\
\text { assist each other when } \\
\text { necessary. }\end{array}$ & & & & & \\
\hline $\begin{array}{l}\text { The team physician is } \\
\text { readily available for } \\
\text { consultation }\end{array}$ & & & & & \\
\hline $\begin{array}{l}\text { I have the authority to } \\
\text { change patient care } \\
\text { procedures. }\end{array}$ & & & & & \\
\hline $\begin{array}{l}\text { Increasing budget for } \\
\text { continuing education } \\
\text { courses, workshops, or } \\
\text { presentations would } \\
\text { increase the quality of care. }\end{array}$ & & & & & \\
\hline $\begin{array}{l}\text { I am satisfied with the } \\
\text { responsibility I have in my } \\
\text { job. }\end{array}$ & & & & & \\
\hline
\end{tabular}

9) Directions: The statements below refer to aspects of care you provide to student athletes. For each statement, please indicate the response that comes closest to your viewpoint at this time. Possible responses range from strongly disagree to strongly agree.

\begin{tabular}{|l|l|l|l|l|l|}
\hline \multirow{2}{*}{} & \multicolumn{4}{|c|}{ Please answer the follow as best as you can. } \\
\cline { 2 - 6 } & $\begin{array}{l}\text { Strongly } \\
\text { disagree }\end{array}$ & $\begin{array}{l}\text { Somewhat } \\
\text { disagree }\end{array}$ & Neutral & $\begin{array}{l}\text { Somewhat } \\
\text { agree }\end{array}$ & $\begin{array}{l}\text { Strongly } \\
\text { agree }\end{array}$ \\
\hline $\begin{array}{l}\text { The persons who evaluate } \\
\text { the performance of the ATs } \\
\text { are knowledgeable about } \\
\text { the duties and } \\
\text { characteristics of the AT } \\
\text { position. }\end{array}$ & & & & & \\
\hline $\begin{array}{l}\text { Supervising physicians are } \\
\text { used to evaluate the } \\
\text { performance of athletic } \\
\text { trainers. }\end{array}$ & & & & & \\
\hline
\end{tabular}


10) Directions: The statements below refer to the quality of care and what you have available to provide that care. For each statement, please indicate the response that comes closest to your viewpoint at this time. Possible responses range from very dissatisfied to very satisfied.

\begin{tabular}{|l|l|l|l|l|l|}
\hline & \multicolumn{3}{|c|}{ Please answer the follow as best as you can. } \\
\cline { 2 - 6 } & $\begin{array}{l}\text { Very } \\
\text { Dissatisfied }\end{array}$ & $\begin{array}{l}\text { Somewhat } \\
\text { dissatisfied }\end{array}$ & Neutral & $\begin{array}{l}\text { Somewhat } \\
\text { satisfied }\end{array}$ & $\begin{array}{l}\text { Very } \\
\text { satisfied }\end{array}$ \\
\hline $\begin{array}{l}\text { I am _ with the quality } \\
\text { of care I provide to } \\
\text { student athletes. }\end{array}$ & & & & \\
\hline $\begin{array}{l}\text { I am _ with the AT } \\
\text { room hours prior to } \\
\text { practice/competition. }\end{array}$ & & & & & \\
\hline $\begin{array}{l}\text { I am _ with how the } \\
\text { AT room is equipped } \\
\text { with the necessary } \\
\text { equipment for quality } \\
\text { care. }\end{array}$ & & & & & \\
\hline $\begin{array}{l}\text { I am with the amount } \\
\text { of medical supplies } \\
\text { provided for use by the } \\
\text { AT staff. }\end{array}$ & & & & & \\
\hline
\end{tabular}


11) Directions: The statements below refer to response time and coverage. For each statement, please indicate the response which comes closest to your viewpoint at this time. Possible responses range from very dissatisfied to very satisfied.

\begin{tabular}{|l|l|l|l|l|l|}
\hline & \multicolumn{3}{|c|}{ Please answer the follow as best as you can. } \\
\cline { 2 - 5 } & $\begin{array}{l}\text { Very } \\
\text { dissatisfied }\end{array}$ & $\begin{array}{l}\text { Somewhat } \\
\text { dissatisfied }\end{array}$ & Neutral & $\begin{array}{l}\text { Somewhat } \\
\text { satisfied }\end{array}$ & $\begin{array}{l}\text { Very } \\
\text { satisfied }\end{array}$ \\
\hline $\begin{array}{l}\text { I am_that the time I } \\
\text { spend at practice is } \\
\text { appropriate to provide } \\
\text { medical supervision. }\end{array}$ & & & & \\
\hline $\begin{array}{l}\text { I am_with my initial } \\
\text { response time to student } \\
\text { athletes injury during a } \\
\text { practice or game. }\end{array}$ & & & & & \\
\hline $\begin{array}{l}\text { I am_that my location } \\
\text { during practice is such } \\
\text { that I am capable of } \\
\text { responding quickly and } \\
\text { appropriately to an } \\
\text { injury. }\end{array}$ & & & & & \\
\hline $\begin{array}{l}\text { I am_with the way } \\
\text { my AT department } \\
\text { handles coverage of } \\
\text { summer conditioning } \\
\text { and skill sessions. }\end{array}$ & & & & & \\
\hline $\begin{array}{l}\text { I am w with the way } \\
\text { my AT department } \\
\text { handles the coverage of } \\
\text { pre-season conditioning } \\
\text { and skill sessions. }\end{array}$ & & & & & \\
\hline $\begin{array}{l}\text { I am w with the way } \\
\text { my AT department } \\
\text { handles coverage of } \\
\text { post-season } \\
\text { conditioning and skill } \\
\text { sessions. }\end{array}$ & & & & & \\
\hline
\end{tabular}


12) Definition:

Athletics model of organization: The athletic training staff is a part of the athletic department and the head athletic trainer reports to the athletics director.

Medical model of organization: The athletic training staff is aligned with campus health services, and the head athletic trainer reports to another healthcare professional, such as the team medical director or physician.

Academic Model of organization: Clinical athletic trainers and athletic training educators are part of the athletic training education program. Practitioners serve dual roles, balancing teaching and clinical responsibilities.

Which model of organization does your school fall under?
a. Athletics
b. Medical
c. Academic

13) What is your current position title?

a. Open-ended field

14) What is the position title of the director of athletic training?

a. Open-ended field

15) What is the position title of your direct supervisor?

a. Open-ended field

16) What number of athletes are your responsible to provide care to?
a. 0-9
b. $10-19$
c. 20-29
d. 30-39
e. 40-49
f. 50-59
g. $60-69$
h. 70-79
i. $80-89$
j. $90-99$
k. 100+ 
17) Please select any administrative duties you currently hold in your position. (Select all that apply)
a. Budget
b. Insurance
c. Coordination of student workers
d. Staff education
e. Computer systems
f. Facility maintenance
g. Scheduling
h. Purchasing
i. Team travel arrangements
j. Athlete education
k. Pre-participation physicals
1. Medical records and injury reporting
m. OSHA
n. Special assistance fund
o. Classroom instruction
p. Drug testing
q. Head athletic trainer
r. Clinical supervisor and instruction to athletic training students
s. Other (Open ended field)

18) What number of full-time ATs are in your department?
a. 0
b. 1
c. 2
d. 3
e. 4
f. 5
g. 6
h. 7
i. 8
j. 9
k. $10+$ 
19) What number of resident ATs are in your department?
a. 0
b. 1
c. 2
d. 3
e. 4
f. 5
g. 6
h. 7
i. 8
j. 9
k. $10+$

20) What number of graduate assistant ATs are in your department?
a. 0
b. 1
c. 2
d. 3
e. 4
f. 5
g. 6
h. 7
i. 8
j. 9
k. $10+$

21) What number of intern ATs are in your department?
a. 0
b. 1
c. 2
d. 3
e. 4
f. 5
g. 6
h. 7
i. 8
j. 9
k. $10+$

22) Are all athletic events (practices and games) supervised by certified ATs?
a. Yes, all practices and games are covered
b. Games are covered but not practices
c. Some practices, some games, depending on the sport
d. None 
23) Please indicate all the sports at your institution that receive care from an AT. (Select all that apply)
a. Archery
b. Badminton
c. Baseball
d. Basketball
e. Beach volleyball
f. Bowling
g. Cross country
h. Equestrian
i. Fencing
j. Field hockey
k. Football
1. Golf
m. Gymnastics
n. Ice hockey
o. Lacrosse
p. Rifle
q. Rowing
r. Rugby
s. Skiing
t. Soccer
u. Softball
v. Squash
w. Swimming and diving
$\mathrm{x}$. Synchronized swimming
y. Tennis
z. Indoor track
aa. Outdoor track
bb. Triathlon
cc. Volleyball
dd. Water polo
ee. Wrestling
ff. Other (open-ended field)

24) "In-season" can be defined as a period of time when any of the sports you are responsible for are in their competitive season.

Average hours worked per week while "in-season"
a. $0-40$
b. $41-59$
c. $60-79$
d. $80+$ 
25) "Off-season" can be defined as a period of time when none of the sports you are responsible for are in their competitive season.

Average hours worked per week in the "off-season"
a. $0-40$
b. $41-59$
c. $60-79$
d. $80+$

26) Gender
a. Male
b. Female
c. Other

27) How many years have you been practicing as a BOC certified AT?
a. $0-4$ years
b. 5-9 years
c. 10-19 years
d. 20-49 years

28) How many years have you worked in the Division I setting?
a. $0-4$ years
b. 5-9 years
c. 10-19 years
d. 20-49 years

29) In which NATA district are you employed?
a. 1
b. 2
c. 3
d. 4
e. 5
f. 6
g. 7
h. 8
i. 9
j. 10

30) What is the highest degree you have earned?
a. Bachelors
b. Masters
c. Doctorate
d. Other (open-ended field) 
31) Which professional credentials do you currently hold? (Select all that apply)
a. ATC
b. CSCS
c. EMT
d. MD
e. OT
f. PA
g. PT
h. PTA
i. Other (Open-ended field

Thank you for your participation! 


\section{APPENDIX D}

\section{ADDITIONAL RESULTS}

Table D1. Demographic Information

\begin{tabular}{ll}
\hline Characteristic & Percent $(\mathrm{n}=66)$ \\
\hline Gender & \\
Male & $53.0 \%(\mathrm{n}=35)$ \\
Female & $47.0 \%(\mathrm{n}=31)$ \\
Years, BOC Certified & \\
0-4 Years & $21.2 \%(\mathrm{n}=14)$ \\
5-9 Years & $30.3 \%(\mathrm{n}=20)$ \\
10-19 Years & $25.8 \%(\mathrm{n}=17)$ \\
20-49 Years & $22.7 \%(\mathrm{n}=15)$ \\
Years, Division I Setting & \\
0-4 Years & $33.3 \%(\mathrm{n}=22)$ \\
5-9 Years & $28.8 \%(\mathrm{n}=19)$ \\
10-19 Years & $24.2 \%(\mathrm{n}=16)$ \\
20-49 Years & $13.6 \%(\mathrm{n}=9)$ \\
NATA District & \\
1 & $4.5 \%(\mathrm{n}=3)$ \\
2 & $7.6 \%(\mathrm{n}=5)$ \\
3 & $24.2 \%(\mathrm{n}=16)$ \\
4 & $21.2 \%(\mathrm{n}=14)$ \\
5 & $3.0 \%(\mathrm{n}=2)$ \\
6 & $7.6 \%(\mathrm{n}=5)$ \\
7 & $10.6 \%(\mathrm{n}=7)$ \\
8 & $12.1 \%(\mathrm{n}=8)$ \\
9 & $7.6 \%(\mathrm{n}=5)$ \\
10 & $1.5 \%(\mathrm{n}=1)$ \\
Highest Degree & \\
Bachelors & $3.0 \%(\mathrm{n}=2)$ \\
Masters & $92.4 \%(\mathrm{n}=61)$ \\
Doctorate & $4.5 \%(\mathrm{n}=3)$ \\
Credentials & \\
ATC & $100.0 \%(\mathrm{n}=66)$ \\
CSCS & $10.6 \%(\mathrm{n}=7)$ \\
CES & $4.5 \%(\mathrm{n}=3)$ \\
EMT & $3.0 \%(\mathrm{n}=2)$ \\
PTA & $3.0 \%(\mathrm{n}=2)$ \\
MD & $1.5 \%(\mathrm{n}=1)$ \\
PES & $1.5 \%(\mathrm{n}=1)$ \\
\hline & \\
\hline
\end{tabular}


Table D2. Administrative Details

\begin{tabular}{|c|c|}
\hline Characteristic & Percent $(n=66)$ \\
\hline \multicolumn{2}{|l|}{ Model of Organization } \\
\hline Athletics & $86.4 \%(\mathrm{n}=57)$ \\
\hline Medical & $10.6 \%(\mathrm{n}=7)$ \\
\hline Academic & $3.0 \%(\mathrm{n}=2)$ \\
\hline \multicolumn{2}{|l|}{ Current Position Title } \\
\hline Assistant/Associate AT & $53.0 \%(\mathrm{n}=35)$ \\
\hline AT & $12.1 \%(n=8)$ \\
\hline Director/Coordinator of AT/Sport Medicine & $10.6 \%(n=7)$ \\
\hline Assistant/Associate AD & $7.6 \%(\mathrm{n}=5)$ \\
\hline Head AT & $4.5 \%(n=3)$ \\
\hline Head AT, Football & $3.0 \%(n=2)$ \\
\hline Assistant/Associate Director & $3.0 \%(\mathrm{n}=2)$ \\
\hline AT 2 & $1.5 \%(\mathrm{n}=1)$ \\
\hline Senior Assistant AT & $1.5 \%(\mathrm{n}=1)$ \\
\hline Senior AT & $1.5 \%(\mathrm{n}=1)$ \\
\hline Senior Director & $1.5 \%(\mathrm{n}=1)$ \\
\hline \multicolumn{2}{|l|}{ Director, Position Title } \\
\hline Assistant/Associate AD & $50.0 \%(\mathrm{n}=33)$ \\
\hline Coordinator/Director of Sports Medicine & $27.3 \%(\mathrm{n}=18)$ \\
\hline Head AT & $13.6 \%(\mathrm{n}=9)$ \\
\hline Senior Associate AD & $3.0 \%(\mathrm{n}=2)$ \\
\hline AT for Volleyball & $1.5 \%(\mathrm{n}=1)$ \\
\hline Executive Director of AT & $1.5 \%(\mathrm{n}=1)$ \\
\hline \multicolumn{2}{|l|}{ Direct Supervisor, Position Title } \\
\hline Assistant/Associate/Deputy AD & $43.9 \%(n=29)$ \\
\hline Director of Sports Medicine/AT & $10.6 \%(\mathrm{n}=7)$ \\
\hline Senior Associate AD & $9.1 \%(n=6)$ \\
\hline Head/Chief AT & $6.0 \%(\mathrm{n}=4)$ \\
\hline Senior Associate AT & $4.5 \%(n=2)$ \\
\hline Executive Associate AD & $1.5 \%(\mathrm{n}=1)$ \\
\hline Executive Director of Sports Medicine/AT & $1.5 \%(\mathrm{n}=1)$ \\
\hline Interim AD & $1.5 \%(\mathrm{n}=1)$ \\
\hline Team Physician & $1.5 \%(\mathrm{n}=1)$ \\
\hline Associate Director, Medical Services & $1.5 \%(\mathrm{n}=1)$ \\
\hline Director of Health Sciences School & $1.5 \%(\mathrm{n}=1)$ \\
\hline
\end{tabular}


Table D3. Responsibilities as an Athletic Trainer

\begin{tabular}{|c|c|}
\hline Responsibility & Percent $(\mathrm{n}=66)$ \\
\hline \multicolumn{2}{|l|}{ Number of Hours Worked, In-Season } \\
\hline $0-40$ & $1.5 \%(\mathrm{n}=1)$ \\
\hline $41-59$ & $28.8 \%(\mathrm{n}=19)$ \\
\hline $60-79$ & $56.1 \%(\mathrm{n}=37)$ \\
\hline $80+$ & $13.6 \%(n=9)$ \\
\hline \multicolumn{2}{|l|}{ Number of Hours Workers, Off-Season } \\
\hline $0-40$ & $28.8 \%(\mathrm{n}=19)$ \\
\hline $41-59$ & $60.6 \%(\mathrm{n}=40)$ \\
\hline $60-79$ & $10.6 \%(\mathrm{n}=7)$ \\
\hline \multicolumn{2}{|l|}{ Number of Athletes } \\
\hline $10-19$ & $12.1 \%(\mathrm{n}=8)$ \\
\hline $20-29$ & $12.1 \%(\mathrm{n}=8)$ \\
\hline $30-39$ & $13.6 \%(\mathrm{n}=9)$ \\
\hline $40-49$ & $7.6 \%(\mathrm{n}=5)$ \\
\hline $50-59$ & $9.1 \%(n=6)$ \\
\hline $60-69$ & $4.5 \%(n=3)$ \\
\hline $70-79$ & $7.6 \%(n=5)$ \\
\hline $80-89$ & $3.0 \%(n=2)$ \\
\hline $90-99$ & $1.5 \%(\mathrm{n}=1)$ \\
\hline $100+$ & $28.8 \%(\mathrm{n}=19)$ \\
\hline \multicolumn{2}{|l|}{ Administrative Duties } \\
\hline Medical Records and Injury Reporting & $93.9 \%(\mathrm{n}=62)$ \\
\hline Pre-Participation Physicals & $81.8 \%(\mathrm{n}=54)$ \\
\hline Clinical Supervisor/Instructor to AT Students & $59.1 \%(\mathrm{n}=39)$ \\
\hline Facility Maintenance & $57.5 \%(\mathrm{n}=38)$ \\
\hline Scheduling & $57.5 \%(\mathrm{n}=38)$ \\
\hline Athlete Education & $57.5 \%(\mathrm{n}=38)$ \\
\hline Coordination of Student Workers & $45.4 \%(\mathrm{n}=30)$ \\
\hline Staff Education & $39.3 \%(\mathrm{n}=26)$ \\
\hline Insurance & $36.3 \%(\mathrm{n}=24)$ \\
\hline Budget & $31.8 \%(\mathrm{n}=21)$ \\
\hline Purchasing & $30.3 \%(n=20)$ \\
\hline Drug Testing & $27.2 \%(\mathrm{n}=18)$ \\
\hline Computer Systems & $25.7 \%(n=17)$ \\
\hline OSHA & $24.2 \%(n=16)$ \\
\hline Head AT & $19.7 \%(\mathrm{n}=13)$ \\
\hline Classroom Instruction & $18.1 \%(\mathrm{n}=12)$ \\
\hline Special Assistance Fund & $9.1 \%(\mathrm{n}=6)$ \\
\hline Team Travel Arrangements & $3.0 \%(n=2)$ \\
\hline Apparel Purchasing & $3.0 \%(n=2)$ \\
\hline Rehabilitation Coordinator & $1.5 \%(n=1)$ \\
\hline
\end{tabular}


Table D4. Staff Size

\begin{tabular}{cl}
\hline Position Category & Percent $(\mathrm{n}=66)$ \\
\hline Number of Full-Time ATs & \\
3 & $4.5 \%(\mathrm{n}=3)$ \\
4 & $7.6 \%(\mathrm{n}=5)$ \\
5 & $7.6 \%(\mathrm{n}=5)$ \\
6 & $10.6 \%(\mathrm{n}=7)$ \\
7 & $21.1 \%(\mathrm{n}=8)$ \\
8 & $4.5 \%(\mathrm{n}=3)$ \\
9 & $13.6 \%(\mathrm{n}=9)$ \\
$10+$ & $39.4 \%(\mathrm{n}=26)$ \\
Number of Resident ATs & \\
0 & $92.4 \%(\mathrm{n}=61)$ \\
2 & $4.5 \%(\mathrm{n}=3)$ \\
3 & $1.5 \%(\mathrm{n}=1)$ \\
5 & $1.5 \%(\mathrm{n}=1)$ \\
Number of Graduate Assistant ATs & \\
0 & $54.5 \%(\mathrm{n}=36)$ \\
1 & $4.5 \%(\mathrm{n}=3)$ \\
2 & $6.1 \%(\mathrm{n}=4)$ \\
3 & $12.1 \%(\mathrm{n}=8)$ \\
4 & $6.1 \%(\mathrm{n}=4)$ \\
5 & $7.6 \%(\mathrm{n}=5)$ \\
6 & $1.5 \%(\mathrm{n}=1)$ \\
7 & $3.0 \%(\mathrm{n}=2)$ \\
8 & $3.0 \%(\mathrm{n}=2)$ \\
$10+$ & $1.5 \%(\mathrm{n}=1)$ \\
Number of Intern ATs & \\
1 & $66.7 \%(\mathrm{n}=44)$ \\
2 & $6.1 \%(\mathrm{n}=4)$ \\
3 & $10.6 \%(\mathrm{n}=7)$ \\
5 & $7.6 \%(\mathrm{n}=5)$ \\
6 & $4.5 \%(\mathrm{n}=3)$ \\
$10+$ & $1.5 \%(\mathrm{n}=1)$ \\
& $1.5 \%(\mathrm{n}=1)$ \\
& $1.5 \%(\mathrm{n}=1)$ \\
\hline
\end{tabular}

Table D5. Staff Size Average by Model

\begin{tabular}{llllll}
\hline Model & Full-Time & Resident & GA & Resident & Total \\
\hline Athletics & 7.86 & 0.19 & 1.68 & 0.91 & 10.64 \\
Medical & 8.00 & 0.43 & 2.28 & 2.00 & 12.71 \\
Academic & 6.50 & 0.00 & 5.00 & 0.00 & 11.50 \\
\hline
\end{tabular}


Table D6. Full-Time AT by Model

\begin{tabular}{lllllllll}
\hline Model & 3 & 4 & 5 & 6 & 7 & 8 & 9 & $10+$ \\
\hline Athletics & 2 & 5 & 5 & 5 & 6 & 3 & 9 & 22 \\
Medical & 1 & 0 & 0 & 1 & 1 & 0 & 0 & 4 \\
Academic & 0 & 0 & 0 & 1 & 1 & 0 & 0 & 0 \\
\hline
\end{tabular}

Table D7. Resident AT by Model

\begin{tabular}{lllll}
\hline Model & 0 & 2 & 3 & 5 \\
\hline Athletics & 53 & 3 & 0 & 1 \\
Medical & 6 & 0 & 1 & 0 \\
Academic & 2 & 0 & 0 & 0 \\
\hline
\end{tabular}

Table D8. Graduate Assistant AT by Model

\begin{tabular}{lllllllllll}
\hline Model & 0 & 1 & 2 & 3 & 4 & 5 & 6 & 7 & 8 & $10+$ \\
\hline Athletics & 30 & 3 & 4 & 8 & 4 & 5 & 1 & 2 & 0 & 0 \\
Medical & 5 & 0 & 0 & 0 & 0 & 0 & 0 & 0 & 2 & 0 \\
Academic & 1 & 0 & 0 & 0 & 0 & 0 & 0 & 0 & 0 & 1 \\
\hline
\end{tabular}

Table D9. Intern AT by Model

\begin{tabular}{lllllllll}
\hline Model & 0 & 1 & 2 & 3 & 4 & 5 & 6 & $10+$ \\
\hline Athletics & 37 & 4 & 7 & 5 & 2 & 1 & 1 & 0 \\
Medical & 5 & 0 & 0 & 0 & 1 & 0 & 0 & 1 \\
Academic & 2 & 0 & 0 & 0 & 0 & 0 & 0 & 0 \\
\hline
\end{tabular}


Table D10. Coverage of NCAA Sports

\begin{tabular}{ll}
\hline Coverage & Percent $(\mathrm{n}=66)$ \\
\hline Events & \\
All Practice and Games & $56.1 \%(\mathrm{n}=37)$ \\
Games, Not Practices & $13.6 \%(\mathrm{n}=9)$ \\
Some Practices, Some Games, Depends on Sport & $30.3 \%(\mathrm{n}=20)$ \\
Sports & \\
Basketball & $97.0 \%(\mathrm{n}=64)$ \\
Soccer & $97.0 \%(\mathrm{n}=64)$ \\
Cross Country & $95.5 \%(\mathrm{n}=63)$ \\
Volleyball & $95.5 \%(\mathrm{n}=63)$ \\
Golf & $93.9 \%(\mathrm{n}=62)$ \\
Outdoor Track & $93.9 \%(\mathrm{n}=62)$ \\
Baseball & $92.4 \%(\mathrm{n}=61)$ \\
Tennis & $89.4 \%(\mathrm{n}=59)$ \\
Indoor Track & $89.4 \%(\mathrm{n}=59)$ \\
Softball & $75.7 \%(\mathrm{n}=50)$ \\
Swimming and Diving & $69.7 \%(\mathrm{n}=46)$ \\
Football & $69.7 \%(\mathrm{n}=46)$ \\
Lacrosse & $50.0 \%(\mathrm{n}=33)$ \\
Wrestling & $31.8 \%(\mathrm{n}=21)$ \\
Rowing & $30.3 \%(\mathrm{n}=20)$ \\
Gymnastics & $27.3 \%(\mathrm{n}=18)$ \\
Field Hockey & $25.8 \%(\mathrm{n}=17)$ \\
Beach Volleyball & $24.2 \%(\mathrm{n}=16)$ \\
Water Polo & $22.7 \%(\mathrm{n}=15)$ \\
Ice Hockey & $13.6 \%(\mathrm{n}=9)$ \\
Fencing & $9.1 \%(\mathrm{n}=6)$ \\
Squash & $7.6 \%(\mathrm{n}=5)$ \\
Bowling & $6.1 \%(\mathrm{n}=4)$ \\
Rugby & $6.1 \%(\mathrm{n}=4)$ \\
Cheerleading/Dance & $6.1 \%(\mathrm{n}=4)$ \\
Rifle & $4.5 \%(\mathrm{n}=3)$ \\
Equestrian & $3.0 \%(\mathrm{n}=2)$ \\
Triathlon & $3.0 \%(\mathrm{n}=2)$ \\
Skiing & $1.5 \%(\mathrm{n}=1)$ \\
Synchronized Swimming & $1.5 \%(\mathrm{n}=1)$ \\
Sailing & $1.5 \%(\mathrm{n}=1)$ \\
\hline & \\
\hline & \\
\hline &
\end{tabular}




\begin{tabular}{|c|c|c|c|c|c|}
\hline Statement & $\begin{array}{l}\text { Strongly } \\
\text { Disagree }\end{array}$ & $\begin{array}{l}\text { Somewhat } \\
\text { Disagree }\end{array}$ & Neutral & $\begin{array}{l}\text { Somewhat } \\
\text { Agree }\end{array}$ & $\begin{array}{l}\text { Strongly } \\
\text { Agree }\end{array}$ \\
\hline $\begin{array}{l}\text { I often find that I } \\
\text { don't complete } \\
\text { everything I should in } \\
\text { my job.*** }\end{array}$ & $\begin{array}{l}9.1 \% \\
(n=6)\end{array}$ & $\begin{array}{l}19.7 \% \\
(n=13)\end{array}$ & $\begin{array}{l}12.1 \% \\
(\mathrm{n}=8)\end{array}$ & $\begin{array}{l}45.5 \% \\
(n=30)\end{array}$ & $\begin{array}{l}12.1 \% \\
(\mathrm{n}=8)\end{array}$ \\
\hline $\begin{array}{l}\text { It is difficult to } \\
\text { manage the athletic } \\
\text { training position if } \\
\text { you are too involved } \\
\text { with the patients. } * * *\end{array}$ & $\begin{array}{l}18.2 \% \\
(n=12)\end{array}$ & $\begin{array}{l}31.8 \% \\
(n=21)\end{array}$ & $\begin{array}{l}12.1 \% \\
(\mathrm{n}=8)\end{array}$ & $\begin{array}{l}28.8 \% \\
(n=19)\end{array}$ & $\begin{array}{l}7.6 \% \\
(n=5)\end{array}$ \\
\hline $\begin{array}{l}\text { I seldom have time to } \\
\text { try and understand } \\
\text { what the patients } \\
\text { think about out } \\
\text { care.*** }\end{array}$ & $\begin{array}{l}30.3 \% \\
(n=20)\end{array}$ & $\begin{array}{l}43.9 \% \\
(n=29)\end{array}$ & $\begin{array}{l}12.1 \% \\
(n=8)\end{array}$ & $\begin{array}{l}12.1 \% \\
(\mathrm{n}=8)\end{array}$ & $\begin{array}{l}0 \% \\
(n=0)\end{array}$ \\
\hline $\begin{array}{l}\text { I am readily available } \\
\text { to the student athletes } \\
\text { for treatment times. }\end{array}$ & $\begin{array}{l}3.0 \% \\
(n=2)\end{array}$ & $\begin{array}{l}6.1 \% \\
(n=4)\end{array}$ & $\begin{array}{l}1.5 \% \\
(n=1)\end{array}$ & $\begin{array}{l}42.4 \% \\
(n=28)\end{array}$ & $\begin{array}{l}45.5 \% \\
(n=30)\end{array}$ \\
\hline $\begin{array}{l}\text { I am readily available } \\
\text { to coaches for } \\
\text { consultation about } \\
\text { student athletes } \\
\text { injury/illness }\end{array}$ & $\begin{array}{l}1.5 \% \\
(n=1)\end{array}$ & $\begin{array}{l}10.6 \% \\
(n=7)\end{array}$ & $\begin{array}{l}3.0 \% \\
(n=2)\end{array}$ & $\begin{array}{l}39.4 \% \\
(n=26)\end{array}$ & $\begin{array}{l}43.9 \% \\
(n=29)\end{array}$ \\
\hline
\end{tabular}

KEY: ** Each statement was scored on a Likert scale of 1 Strongly Disagree, 2 Somewhat Disagree, 3 Neutral, 4 Somewhat Agree, 5 Strongly Agree.

*** This question was reverse coded on the Likert scale of 5 Strongly Disagree, 4 Somewhat Disagree, 3 Neutral, 2 Somewhat Agree, 1 Strongly Agree 
Table D12. Response to Survey Question Six **

\begin{tabular}{|c|c|c|c|c|c|}
\hline Statement & $\begin{array}{l}\text { Strongly } \\
\text { Disagree }\end{array}$ & $\begin{array}{l}\text { Somewhat } \\
\text { Disagree }\end{array}$ & Neutral & $\begin{array}{l}\text { Somewhat } \\
\text { Agree }\end{array}$ & $\begin{array}{l}\text { Strongly } \\
\text { Agree }\end{array}$ \\
\hline $\begin{array}{l}\text { Providing colleague } \\
\text { support } \\
\text { network/mechanisms } \\
\text { would increase the } \\
\text { quality of care. }\end{array}$ & $\begin{array}{l}0.0 \% \\
(\mathrm{n}=0)\end{array}$ & $\begin{array}{l}0.0 \% \\
(\mathrm{n}=0)\end{array}$ & $\begin{array}{l}13.6 \% \\
(\mathrm{n}=9)\end{array}$ & $\begin{array}{l}51.5 \% \\
(\mathrm{n}=34)\end{array}$ & $\begin{array}{l}34.8 \% \\
(\mathrm{n}=23)\end{array}$ \\
\hline $\begin{array}{l}\text { The patients at work } \\
\text { nearly always receive } \\
\text { good care. }\end{array}$ & $\begin{array}{l}1.5 \% \\
(\mathrm{n}=1)\end{array}$ & $\begin{array}{l}4.5 \% \\
(n=3)\end{array}$ & $\begin{array}{l}7.6 \% \\
(\mathrm{n}=5)\end{array}$ & $\begin{array}{l}51.5 \% \\
(\mathrm{n}=34)\end{array}$ & $\begin{array}{l}34.8 \% \\
(\mathrm{n}=23)\end{array}$ \\
\hline $\begin{array}{l}\text { When a student } \\
\text { athlete enters the AT } \\
\text { room they do not } \\
\text { have to wait for more } \\
\text { than } 10 \text { minutes for } \\
\text { an AT to complete } \\
\text { work with other } \\
\text { athletes before they } \\
\text { are seen. }\end{array}$ & $\begin{array}{l}6.1 \% \\
(\mathrm{n}=4)\end{array}$ & $\begin{array}{l}12.1 \% \\
(\mathrm{n}=8)\end{array}$ & $\begin{array}{l}7.6 \% \\
(\mathrm{n}=5)\end{array}$ & $\begin{array}{l}33.3 \% \\
(\mathrm{n}=22)\end{array}$ & $\begin{array}{l}40.9 \% \\
(\mathrm{n}=27)\end{array}$ \\
\hline $\begin{array}{l}\text { I collaborate and } \\
\text { consult with other } \\
\text { ATs or other medical } \\
\text { professionals when I } \\
\text { am unsure of an } \\
\text { injury. }\end{array}$ & $\begin{array}{l}0.0 \% \\
(\mathrm{n}=0)\end{array}$ & $\begin{array}{l}1.5 \% \\
(\mathrm{n}=1)\end{array}$ & $\begin{array}{l}1.5 \% \\
(\mathrm{n}=1)\end{array}$ & $\begin{array}{l}22.7 \% \\
(n=15)\end{array}$ & $\begin{array}{l}74.2 \% \\
(\mathrm{n}=49)\end{array}$ \\
\hline $\begin{array}{l}\text { As a staff, ways of } \\
\text { improving the care } \\
\text { provided to athletes is } \\
\text { discussed. }\end{array}$ & $\begin{array}{l}1.5 \% \\
(\mathrm{n}=1)\end{array}$ & $\begin{array}{l}9.1 \% \\
(\mathrm{n}=6)\end{array}$ & $\begin{array}{l}10.6 \% \\
(n=7)\end{array}$ & $\begin{array}{l}47.0 \% \\
(\mathrm{n}=31)\end{array}$ & $\begin{array}{l}31.8 \% \\
(\mathrm{n}=21)\end{array}$ \\
\hline
\end{tabular}

KEY: ** Each statement was scored on a Likert scale of 1 Strongly Disagree, 2 Somewhat Disagree, 3 Neutral, 4 Somewhat Agree, 5 Strongly Agree. 
Table D13. Response to Survey Question Seven**

\begin{tabular}{|c|c|c|c|c|c|}
\hline Statement & $\begin{array}{l}\text { Strongly } \\
\text { Disagree }\end{array}$ & $\begin{array}{l}\text { Somewhat } \\
\text { Disagree }\end{array}$ & Neutral & $\begin{array}{l}\text { Somewhat } \\
\text { Agree }\end{array}$ & $\begin{array}{l}\text { Strongly } \\
\text { Agree }\end{array}$ \\
\hline $\begin{array}{l}\text { My supervisor is able } \\
\text { to manage the } \\
\text { department as a while } \\
\text { team to enable } \\
\text { everyone's needs to } \\
\text { be met. }\end{array}$ & $\begin{array}{l}13.6 \% \\
(\mathrm{n}=9)\end{array}$ & $\begin{array}{l}15.2 \% \\
(\mathrm{n}=10)\end{array}$ & $\begin{array}{l}12.1 \% \\
(\mathrm{n}=8)\end{array}$ & $\begin{array}{l}40.9 \% \\
(\mathrm{n}=27)\end{array}$ & $\begin{array}{l}18.2 \% \\
(\mathrm{n}=12)\end{array}$ \\
\hline $\begin{array}{l}\text { My supervisor thinks } \\
\text { about how the work } \\
\text { in my department can } \\
\text { be organized to } \\
\text { jointly benefit } \\
\text { employees and the } \\
\text { company. }\end{array}$ & $\begin{array}{l}10.6 \% \\
(\mathrm{n}=7)\end{array}$ & $\begin{array}{l}15.2 \% \\
(\mathrm{n}=10)\end{array}$ & $\begin{array}{l}16.7 \% \\
(\mathrm{n}=11)\end{array}$ & $\begin{array}{l}37.9 \% \\
(\mathrm{n}=25)\end{array}$ & $\begin{array}{l}19.7 \% \\
(\mathrm{n}=13)\end{array}$ \\
\hline $\begin{array}{l}\text { I can depend on my } \\
\text { supervisor to help me } \\
\text { with scheduling } \\
\text { conflicts if needed. }\end{array}$ & $\begin{array}{l}6.1 \% \\
(\mathrm{n}=4)\end{array}$ & $\begin{array}{l}6.1 \% \\
(\mathrm{n}=4)\end{array}$ & $\begin{array}{l}12.1 \% \\
(\mathrm{n}=8)\end{array}$ & $\begin{array}{l}34.8 \% \\
(\mathrm{n}=23)\end{array}$ & $\begin{array}{l}40.9 \% \\
(\mathrm{n}=27)\end{array}$ \\
\hline $\begin{array}{l}\text { My supervisor is } \\
\text { creative in } \\
\text { reallocating job } \\
\text { duties to help my } \\
\text { department work } \\
\text { better as a team. }\end{array}$ & $\begin{array}{l}13.6 \% \\
(\mathrm{n}=9)\end{array}$ & $\begin{array}{l}21.2 \% \\
(\mathrm{n}=14)\end{array}$ & $\begin{array}{l}21.2 \% \\
(\mathrm{n}=14)\end{array}$ & $\begin{array}{l}25.8 \% \\
(\mathrm{n}=17)\end{array}$ & $\begin{array}{l}18.2 \% \\
(\mathrm{n}=12)\end{array}$ \\
\hline $\begin{array}{l}\text { The division of } \\
\text { responsibility in our } \\
\text { department works } \\
\text { well. }\end{array}$ & $\begin{array}{l}9.1 \% \\
(\mathrm{n}=6)\end{array}$ & $\begin{array}{l}25.8 \% \\
(\mathrm{n}=17)\end{array}$ & $\begin{array}{l}18.2 \% \\
(\mathrm{n}=12)\end{array}$ & $\begin{array}{l}30.3 \% \\
(\mathrm{n}=20)\end{array}$ & $\begin{array}{l}16.7 \% \\
(\mathrm{n}=11)\end{array}$ \\
\hline
\end{tabular}

KEY: ** Each statement was scored on a Likert scale of 1 Strongly Disagree, 2 Somewhat Disagree, 3 Neutral, 4 Somewhat Agree, 5 Strongly Agree. 
Table D14. Response to Survey Question Eight**

\begin{tabular}{|c|c|c|c|c|c|}
\hline Statement & $\begin{array}{l}\text { Strongly } \\
\text { Disagree }\end{array}$ & $\begin{array}{l}\text { Somewhat } \\
\text { Disagree }\end{array}$ & Neutral & $\begin{array}{l}\text { Somewhat } \\
\text { Agree }\end{array}$ & $\begin{array}{l}\text { Strongly } \\
\text { Agree }\end{array}$ \\
\hline $\begin{array}{l}\text { Generally, my co- } \\
\text { workers and I work } \\
\text { as a team and assist } \\
\text { each other when } \\
\text { necessary. }\end{array}$ & $\begin{array}{l}1.5 \% \\
(\mathrm{n}=1)\end{array}$ & $\begin{array}{l}7.6 \% \\
(n=5)\end{array}$ & $\begin{array}{l}4.5 \% \\
(n=3)\end{array}$ & $\begin{array}{l}42.4 \% \\
(n=28)\end{array}$ & $\begin{array}{l}43.9 \% \\
(n=29)\end{array}$ \\
\hline $\begin{array}{l}\text { The team physician is } \\
\text { readily available for } \\
\text { consultation. }\end{array}$ & $\begin{array}{l}0.0 \% \\
(\mathrm{n}=0)\end{array}$ & $\begin{array}{l}6.1 \% \\
(n=4)\end{array}$ & $\begin{array}{l}7.6 \% \\
(n=5)\end{array}$ & $\begin{array}{l}37.9 \% \\
(\mathrm{n}=25)\end{array}$ & $\begin{array}{l}48.5 \% \\
(n=32)\end{array}$ \\
\hline $\begin{array}{l}\text { I have the authority to } \\
\text { change patient care } \\
\text { procedures. }\end{array}$ & $\begin{array}{l}0.0 \% \\
(\mathrm{n}=0)\end{array}$ & $\begin{array}{l}4.5 \% \\
(n=3)\end{array}$ & $\begin{array}{l}12.1 \% \\
(\mathrm{n}=8)\end{array}$ & $\begin{array}{l}36.4 \% \\
(\mathrm{n}=24)\end{array}$ & $\begin{array}{l}45.5 \% \\
(\mathrm{n}=30)\end{array}$ \\
\hline $\begin{array}{l}\text { Increasing budget for } \\
\text { continuing education } \\
\text { courses, workshops, } \\
\text { or presentations } \\
\text { would increase the } \\
\text { quality of care. }\end{array}$ & $\begin{array}{l}3.0 \% \\
(\mathrm{n}=2)\end{array}$ & $\begin{array}{l}6.1 \% \\
(n=4)\end{array}$ & $\begin{array}{l}19.7 \% \\
(\mathrm{n}=13)\end{array}$ & $\begin{array}{l}30.3 \% \\
(\mathrm{n}=20)\end{array}$ & $\begin{array}{l}40.9 \% \\
(\mathrm{n}=27)\end{array}$ \\
\hline $\begin{array}{l}\text { I am satisfied with } \\
\text { the responsibility I } \\
\text { have in my job. }\end{array}$ & $\begin{array}{l}6.1 \% \\
(\mathrm{n}=4)\end{array}$ & $\begin{array}{l}12.1 \% \\
(\mathrm{n}=8)\end{array}$ & $\begin{array}{l}10.6 \% \\
(n=7)\end{array}$ & $\begin{array}{l}51.5 \% \\
(\mathrm{n}=34)\end{array}$ & $\begin{array}{l}19.7 \% \\
(\mathrm{n}=13)\end{array}$ \\
\hline
\end{tabular}

KEY: ** Each statement was scored on a Likert scale of 1 Strongly Disagree, 2 Somewhat Disagree, 3 Neutral, 4 Somewhat Agree, 5 Strongly Agree. 
Table D15. Response to Survey Question Nine**

\begin{tabular}{|c|c|c|c|c|c|}
\hline Statement & $\begin{array}{l}\text { Strongly } \\
\text { Disagree }\end{array}$ & $\begin{array}{l}\text { Somewhat } \\
\text { Disagree }\end{array}$ & Neutral & $\begin{array}{l}\text { Somewhat } \\
\text { Agree }\end{array}$ & $\begin{array}{l}\text { Strongly } \\
\text { Agree }\end{array}$ \\
\hline $\begin{array}{l}\text { The persons who } \\
\text { evaluate the } \\
\text { performance of the } \\
\text { ATs are } \\
\text { knowledgeable about } \\
\text { the duties and } \\
\text { characteristics of the } \\
\text { AT position. }\end{array}$ & $\begin{array}{l}12.1 \% \\
(\mathrm{n}=8)\end{array}$ & $\begin{array}{l}18.2 \% \\
(\mathrm{n}=12)\end{array}$ & $\begin{array}{l}10.6 \% \\
(\mathrm{n}=7)\end{array}$ & $\begin{array}{l}19.7 \% \\
(\mathrm{n}=13)\end{array}$ & $\begin{array}{l}39.4 \% \\
(\mathrm{n}=26)\end{array}$ \\
\hline $\begin{array}{l}\text { Supervising } \\
\text { physicians are used to } \\
\text { evaluate the } \\
\text { performance of ATs }\end{array}$ & $\begin{array}{l}43.9 \% \\
(\mathrm{n}=29)\end{array}$ & $\begin{array}{l}16.7 \% \\
(\mathrm{n}=11)\end{array}$ & $\begin{array}{l}19.7 \% \\
(\mathrm{n}=13)\end{array}$ & $\begin{array}{l}12.1 \% \\
(\mathrm{n}=8)\end{array}$ & $\begin{array}{l}7.6 \% \\
(n=5)\end{array}$ \\
\hline
\end{tabular}

KEY: ** Each statement was scored on a Likert scale of 1 Strongly Disagree, 2 Somewhat Disagree, 3 Neutral, 4 Somewhat Agree, 5 Strongly Agree.

Table D16. Response to Survey Question Ten**

\begin{tabular}{|c|c|c|c|c|c|}
\hline Statement & $\begin{array}{l}\text { Very } \\
\text { Dissatisfied }\end{array}$ & $\begin{array}{l}\text { Somewhat } \\
\text { Dissatisfied }\end{array}$ & Neutral & $\begin{array}{l}\text { Somewhat } \\
\text { Satisfied }\end{array}$ & $\begin{array}{l}\text { Very } \\
\text { Satisfied }\end{array}$ \\
\hline $\begin{array}{l}\text { I am _ with the } \\
\text { quality of care I } \\
\text { provide to student } \\
\text { athletes. }\end{array}$ & $\begin{array}{l}1.5 \% \\
(\mathrm{n}=1)\end{array}$ & $\begin{array}{l}1.5 \% \\
(\mathrm{n}=1)\end{array}$ & $\begin{array}{l}1.5 \% \\
(\mathrm{n}=1)\end{array}$ & $\begin{array}{l}57.6 \% \\
(\mathrm{n}=38)\end{array}$ & $\begin{array}{l}37.9 \% \\
(\mathrm{n}=25)\end{array}$ \\
\hline $\begin{array}{l}\text { I am _ with the AT } \\
\text { room hours prior to } \\
\text { practice/competition. }\end{array}$ & $\begin{array}{l}1.5 \% \\
(\mathrm{n}=1)\end{array}$ & $\begin{array}{l}15.2 \% \\
(\mathrm{n}=10)\end{array}$ & $\begin{array}{l}4.5 \% \\
(\mathrm{n}=3)\end{array}$ & $\begin{array}{l}33.3 \% \\
(\mathrm{n}=22)\end{array}$ & $\begin{array}{l}45.5 \% \\
(n=30)\end{array}$ \\
\hline $\begin{array}{l}\text { I am _ with how the } \\
\text { AT room is equipped } \\
\text { with the necessary } \\
\text { equipment for quality } \\
\text { care. }\end{array}$ & $\begin{array}{l}6.1 \% \\
(n=4)\end{array}$ & $\begin{array}{l}22.7 \% \\
(\mathrm{n}=15)\end{array}$ & $\begin{array}{l}4.5 \% \\
(\mathrm{n}=3)\end{array}$ & $\begin{array}{l}39.4 \% \\
(n=26)\end{array}$ & $\begin{array}{l}27.3 \% \\
(\mathrm{n}=18)\end{array}$ \\
\hline $\begin{array}{l}\text { I am _ with the } \\
\text { amount of medical } \\
\text { supplies provided for } \\
\text { use by the AT staff. }\end{array}$ & $\begin{array}{l}4.5 \% \\
(n=3)\end{array}$ & $\begin{array}{l}9.1 \% \\
(\mathrm{n}=6)\end{array}$ & $\begin{array}{l}6.1 \% \\
(\mathrm{n}=4)\end{array}$ & $\begin{array}{l}45.5 \% \\
(\mathrm{n}=30)\end{array}$ & $\begin{array}{l}34.8 \% \\
(\mathrm{n}=23)\end{array}$ \\
\hline
\end{tabular}

KEY: ** Each statement was scored on a Likert scale of 1 Very Dissatisfied, 2 Somewhat Dissatisfied, 3 Neutral, 4 Somewhat Satisfied, 5 Very Satisfied. 
Table D17. Response to Survey Question Eleven**

\begin{tabular}{|c|c|c|c|c|c|}
\hline Statement & $\begin{array}{l}\text { Very } \\
\text { Dissatisfied }\end{array}$ & $\begin{array}{l}\text { Somewhat } \\
\text { Dissatisfied }\end{array}$ & Neutral & $\begin{array}{l}\text { Somewhat } \\
\text { Satisfied }\end{array}$ & $\begin{array}{l}\text { Very } \\
\text { Satisfied }\end{array}$ \\
\hline $\begin{array}{l}\text { I am_that the time } \\
\text { I spend at practice is } \\
\text { appropriate to } \\
\text { provide proper } \\
\text { medical supervision. }\end{array}$ & $\begin{array}{l}4.5 \% \\
(n=3)\end{array}$ & $\begin{array}{l}7.6 \% \\
(n=5)\end{array}$ & $\begin{array}{l}6.1 \% \\
(\mathrm{n}=4)\end{array}$ & $\begin{array}{l}34.8 \% \\
(\mathrm{n}=23)\end{array}$ & $\begin{array}{l}47.0 \% \\
(\mathrm{n}=31)\end{array}$ \\
\hline $\begin{array}{l}\text { I am _ with my } \\
\text { initial response time } \\
\text { to student athletes } \\
\text { injury during a } \\
\text { practice or game. }\end{array}$ & $\begin{array}{l}0.0 \% \\
(\mathrm{n}=0)\end{array}$ & $\begin{array}{l}1.5 \% \\
(\mathrm{n}=1)\end{array}$ & $\begin{array}{l}1.5 \% \\
(\mathrm{n}=1)\end{array}$ & $\begin{array}{l}19.7 \% \\
(\mathrm{n}=13)\end{array}$ & $\begin{array}{l}77.3 \% \\
(\mathrm{n}=51)\end{array}$ \\
\hline $\begin{array}{l}\text { I am _ that my } \\
\text { location during } \\
\text { practice is such that I } \\
\text { am capable of } \\
\text { responding quickly } \\
\text { and appropriately to } \\
\text { an injury. }\end{array}$ & $\begin{array}{l}0.0 \% \\
(\mathrm{n}=0)\end{array}$ & $\begin{array}{l}4.5 \% \\
(\mathrm{n}=3)\end{array}$ & $\begin{array}{l}1.5 \% \\
(\mathrm{n}=1)\end{array}$ & $\begin{array}{l}18.2 \% \\
(\mathrm{n}=12)\end{array}$ & $\begin{array}{l}75.8 \% \\
(\mathrm{n}=50)\end{array}$ \\
\hline $\begin{array}{l}\text { I am _ with the way } \\
\text { my AT department } \\
\text { handles the coverage } \\
\text { of summer } \\
\text { conditioning and skill } \\
\text { sessions. }\end{array}$ & $\begin{array}{l}4.5 \% \\
(n=3)\end{array}$ & $\begin{array}{l}21.2 \% \\
(\mathrm{n}=14)\end{array}$ & $\begin{array}{l}19.7 \% \\
(n=13)\end{array}$ & $\begin{array}{l}18.2 \% \\
(\mathrm{n}=12)\end{array}$ & $\begin{array}{l}36.4 \% \\
(\mathrm{n}=24)\end{array}$ \\
\hline $\begin{array}{l}\text { I am _- with the way } \\
\text { my AT department } \\
\text { handles the coverage } \\
\text { of pre-season } \\
\text { conditioning and skill } \\
\text { sessions. }\end{array}$ & $\begin{array}{l}1.5 \% \\
(\mathrm{n}=1)\end{array}$ & $\begin{array}{l}13.6 \% \\
(\mathrm{n}=9)\end{array}$ & $\begin{array}{l}10.6 \% \\
(\mathrm{n}=7)\end{array}$ & $\begin{array}{l}39.4 \% \\
(\mathrm{n}=26)\end{array}$ & $\begin{array}{l}34.8 \% \\
(\mathrm{n}=23)\end{array}$ \\
\hline $\begin{array}{l}\text { I am _ with the way } \\
\text { my AT department } \\
\text { handles the coverage } \\
\text { of post-season } \\
\text { conditioning and skill } \\
\text { sessions. }\end{array}$ & $\begin{array}{l}1.5 \% \\
(\mathrm{n}=1)\end{array}$ & $\begin{array}{l}15.2 \% \\
(n=10)\end{array}$ & $\begin{array}{l}15.2 \% \\
(n=10)\end{array}$ & $\begin{array}{l}34.8 \% \\
(\mathrm{n}=23)\end{array}$ & $\begin{array}{l}33.3 \% \\
(\mathrm{n}=22)\end{array}$ \\
\hline
\end{tabular}

KEY: ** Each statement was scored on a Likert scale of 1 Very Dissatisfied, 2 Somewhat Dissatisfied, 3 Neutral, 4 Somewhat Satisfied, 5 Very Satisfied. 
Table D18. Likert Average by Category**

\begin{tabular}{ll}
\hline Category & Percent $(\mathrm{n}=66)$ \\
\hline Quality of Care (Questions 5-9) & \\
2.00-2.99 & $7.6 \%(\mathrm{n}=5)$ \\
$3.00-3.99$ & $60.6 \%(\mathrm{n}=40)$ \\
4.00-5.00 & $31.8 \%(\mathrm{n}=21)$ \\
Care Focus (Question 10) & $1.5 \%(\mathrm{n}=1)$ \\
$1.00-1.99$ & $6.1 \%(\mathrm{n}=4)$ \\
$2.00-2.99$ & $31.8 \%(\mathrm{n}=21)$ \\
3.00-3.99 & $60.6 \%(\mathrm{n}=40)$ \\
4.00-5.00 & \\
Coverage Focus (Question 11) & $6.1 \%(\mathrm{n}=4)$ \\
2.00-2.99 & $25.8 \%(\mathrm{n}=17)$ \\
3.00-3.99 & $68.2 \%(\mathrm{n}=45)$ \\
4.00-5.00 &
\end{tabular}

KEY: ** Likert Average was calculated using the average numeric response from the respective questions in each category.

Table D19. Categorical Distribution**

\begin{tabular}{ll}
\hline Category & Percent $(\mathrm{n}=66)$ \\
\hline Quality of Care & \\
$\quad$ Low Quality & $25.7 \%(\mathrm{n}=17)$ \\
$\quad$ High Quality & $74.2 \%(\mathrm{n}=49)$ \\
Care Focus & $22.4 \%(\mathrm{n}=15)$ \\
$\quad$ Low Care Focus & $77.3 \%(\mathrm{n}=51)$ \\
High Care Focus & \\
Coverage Focus & $19.7 \%(\mathrm{n}=13)$ \\
$\quad$ Low Coverage Focus & $80.3 \%(\mathrm{n}=53)$ \\
$\quad$ High Coverage Focus &
\end{tabular}

KEY: ** Participants were distributed into categories based on their average score found in Table D13. Low category $<3.5$ average, High Category $\geq 3.5$ average.

Table D20. Quality of Care Category and Model of Organization

\begin{tabular}{llll}
\hline Model & Low Quality & High Quality & Fisher's Exact \\
\hline Athletics $(\mathrm{n}=57)$ & $26.3 \%(\mathrm{n}=15)$ & $73.7 \%(\mathrm{n}=42)$ & $\sum=6.614^{*}, \mathrm{P}=.021,2$ \\
Medical $(\mathrm{n}=7)$ & $0.0 \%(\mathrm{n}=0)$ & $100.0 \%(\mathrm{n}=7)$ & \\
Academic $(\mathrm{n}=2)$ & $100.0 \%(\mathrm{n}=2)$ & $0.0 \%(\mathrm{n}=0)$ & \\
\hline
\end{tabular}

KEY: * significant finding at $\mathrm{P}<.05$

Table D21. Care Focus and Model of Organization

\begin{tabular}{llll}
\hline Model & Low Care & High Care & Fisher's Exact \\
\hline Athletics $(\mathrm{n}=57)$ & $22.8 \%(\mathrm{n}=13)$ & $77.2 \%(\mathrm{n}=44)$ & $\sum=1.426, \mathrm{P}=.608,2$ \\
Medical $(\mathrm{n}=7)$ & $14.6 \%(\mathrm{n}=1)$ & $85.7 \%(\mathrm{n}=6)$ & \\
Academic $(\mathrm{n}=2)$ & $50.0 \%(\mathrm{n}=1)$ & $50.0 \%(\mathrm{n}=1)$ & \\
\hline
\end{tabular}


Table D22. Coverage Focus and Model of Organization

\begin{tabular}{llll}
\hline Model & Low Coverage & High Coverage & Fisher's Exact \\
\hline Athletics $(\mathrm{n}=57)$ & $21.1 \%(\mathrm{n}=12)$ & $78.9 \%(\mathrm{n}=45)$ & $\sum=0.357, \mathrm{P}=1.000,2$ \\
Medical $(\mathrm{n}=7)$ & $14.3 \%(\mathrm{n}=1)$ & $85.7 \%(\mathrm{n}=6)$ & \\
Academic $(\mathrm{n}=2)$ & $0.0 \%(\mathrm{n}=0)$ & $100.0 \%(\mathrm{n}=2)$ & \\
\hline
\end{tabular}




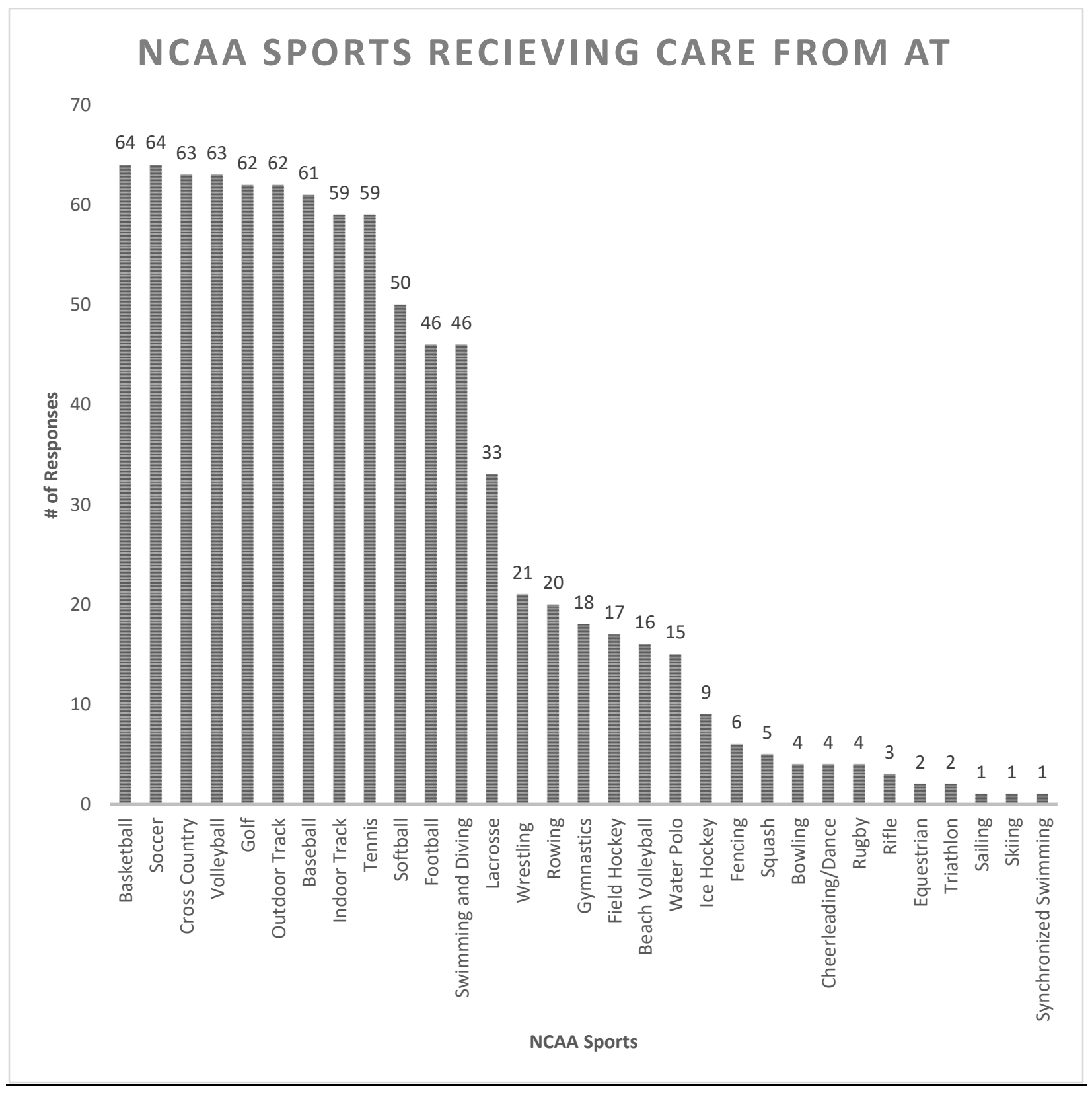




\section{APPENDIX E}

\section{RECOMMENDATIONS FOR FUTURE RESEARCH}

1. Evaluate the team physician's perspective on the quality of care delivered by the athletic trainers in the department.

2. Obtain a sample of even distribution in the athletics, medical, and academic model of organization by creating a list of potential participants through professional networks.

3. Increase the response rate by conducting survey in a controlled environment such as at a professional conference for college athletic trainers (Intercollegiate Council for Sports Medicine Annual Meeting).

4. Validate a questionnaire for the athletic trainer, team physician, and patient's perspective on quality of care in athletic training. This can be accomplished by formally analyzing the questionnaire for face validity and formally pilot the study with athletic trainers, team physicians, and patients.

5. Conduct a qualitative study to include in-person interviews of athletic trainers, team physicians, athletes, and athletic directors. This will be based on results from previous research completed on the topic of quality of care in athletic training.

6. Include athletic trainers from NCAA Division II and Division III. 


\section{ADDITIONAL REFERENCES}

51. Davies HTO, Nutley SM, Mannion R. Organizational culture and quality of health care. Qual in Heal Care. 2000:9;111-119.

52. Joseph S. Transition from fee-for-service to value-based health care model. [Master Capstone]. Utica, NY: Utica College; 2017.

53. Ware JE, Bayliss MS, Rogers WH, Kosinski M, Tarlov AR. Differences in 4-year health outcomes for elderly and poor, chronically ill patients treated in HMO and fee-for-service systems: results from the medical outcomes study. JAMA. 1996;276(13):1039-1047.

54. Arnetz JE, Almin I, Bergstrom K, Franzen Y, Nilsson H. Active patient involvement in the establishment of physical therapy goals: effects on treatment outcomes and quality of care. Adv Physiother. 2004;6:50-69.

55. Arora NK, McHorney CA. Patient preferences for medical decision making: who really wants to participate? Med Care. 2000;38:335-341.

56. Young A, Flower L. Patients as partners, patients as problem-solvers. Health Commun. 2002;14:69-97.

57. Baker SM, Marshak HH, Rice GT, Zimmerman GJ. Patient participation in physical therapy goal setting. Phys Ther. 2001;81:1118-1126.

58. Waddington I. Ethical problems in the medical management of sports injuries: A case study of English professional football. In: Loland S, Skirstad B Waddington I, eds. Pain and Injury in Sport: Social and Ethical Analysis. New York, NY: Routledge; 2006:182-199.

59. Wolverton B. Coach makes the call: athletic trainers who butt heads with coaches over concussion treatment take career hits. The Chronicle of Higher Education Web site. http://www.chronicle.com/article/Trainers-Butt-Heads-With/14133. Published September 2, 2013. Assessed August 29, 2018.

60. Mazerolle SM, Bruening JE, Casa DJ. Work-family conflict, part I: Antecedents of workfamily conflict in national collegiate athletic association division I-A certified athletic trainers. J Athl Train. 2008;43(5):505-512.

61. Henderson J. The 2015 athletic trainer practice analysis study. Omaha, NE; Board of Certification; 2015

62. Robinson JH, Callister LC, Berry JA, Dearing KA. Patient centered care and adherence: definitions and applications to improve outcomes. J Am Acad Nurse Pract. 2008;20(12):600607. 
63. Wynia M, Matiasek J. Promising practices for patient-centered communication with vulnerable populations: examples from eight hospitals. Commonwealth Fund. 2006:1-94.

64. Kitson A. Indicators of quality in nursing care- an alternative approach. $J$ of Adv Nurs. 1986;11:133-144.

65. Laschinger HS, McGillis Hall L, Almost J. A psychometric analysis of the patient satisfaction with nursing care quality questionnaire. J Nurs Care Qual. 2005;20(3):220-230.

66. Chen SS, Unruh M, Williams M. In quality we trust; but quality of life or quality of care? Semin Dial. 2016;29(2):103-110.

67. Blegen MA, Vaughn T. A multisite study of nurse staffing and patient occurrences. Nurs Econ. 1998:16(4);196-203.

68. Aiken LH, Clarke SP, Sloane DM, Sochalski J, Silber JH. Hospital nurse staffing and patient mortality, nurse burnout, and job dissatisfaction. JAMA. 2002; 2888:1987-1993.

69. Raab S, Wolfe BD, Gould TE, Piland SG. Characterizations of a quality certified athletic trainer. J Athl Train. 2011:46(6);672-679.

70. Dang D, Johantgen ME, Pronovost PJ, Jenckes MW, Bass EB. Postoperative complications: does intensive care unit staff nursing make a difference? Heart Lung J Acute Crit Care. 2002; 31: 219-228.

71. Jensen GM, Shepard KF, Gwyer J, Hack LM. The novice versus the experienced clinician: insights into the work of the physical therapist. Phys Ther. 1990;70:314-323.

72. Jensen GM, Gwyer J, Shepard KF, Hack LM. Expert practice in physical therapy. Phys Ther. 2000;80:28-52.

73. Donabedian A. Explorations in quality assessment and monitoring. volume 1: The definition of quality and approaches to its assessment. Ann Arbor, MI: Health Administration Press; 1980.

74. Beck RS, Daughtridge R, Sloane PD. Physician-patient communication in the primary care office: a systematic review. J Am Board Fam Pract. 2002;15(1):25-38.

75. Barry MJ, Edgman-Levitan S. Shared decision making - The pinnacle of patient-centered care. N Engl J Med. 2012;266(9):780-781.

76. Rimal RN. Analyzing the physician-patient interaction: an overview of six methods and future research directions. Health Commun. 2001;13(1):89-99.

77. Steffen GE. Quality medical care: a definition. JAMA. 1988;160(1):56-61. 
78. Blumenthal, D. Quality of care- what is it? N Engl J Med. 1996;335:891-894.

79. McKenna HP, Keeney S, Currie L et al. Quality of care: a comparison of perceptions of health professionals in clinical areas in the united kingdom and the united states. $J$ Nurs Care Qual. 2006;21(4):344-351.

80. Cassel CK. Quality of care and quality of training: a shared vision for internal medicine? Ann Intern Med. 2004;140:927-928.

81. Goldenberg MJ. Defining "quality of care" persuasively. Theor Med Bioeth. 2012;33:243261.

82. Committee on Quality Health Care in America, Institute of Medicine. Crossing the quality chasm: a new health system for the $21^{\text {st }}$ century. National Academy Press; 2001.

83. Shine KI. Health care quality and how to achieve it. Acad Med. 2002;77(1):91-99.

84. Moss F, Garside P, Dawson S. Organisational change: the key to quality improvement. Qual Health Care. 1998;7(Suppl):S1-2.

85. Koeck C. Time for organizational development in healthcare organisations. BMJ. 1998;317:1267-1268.

86. Lukas CV, Holmes SK, Cohen AB, et al. Transformational change in health care systems: an organizational model. Health Care Manage Rev. 2007;32(4):309-320.

87. Needleman J, Pearson M, Parketon P et al. Transforming care at the bedside: lessons learned from phase II. 2007. Available at :

http://www.rwjf.org/files/research/20071015tcabphase2lessonsfinal.pdf. Accessed December $5,2018$.

88. Varkey P, Reller MK, Resar RK. Basics of quality improvement in health care. Mayo Clin Proc. 2007;82(6):735-739.

89. Malasarn R, Bloom GA, Crumpton R. The development of expert male national collegiate athletic association division I certified athletic trainers. J Athl Train. 2002;37(1):55-62.

90. Hudson MB, Irwin Z. Uncovering organizational culture: a necessary skill for athletic trainers. Athl Ther Today. 2010:15(1);4-8.

91. Mazerolle SM, Eason CM. The organizational climate in collegiate athletics: an athletic trainer's perspective. J Athl Train. 2018:53(1);88-97.

92. Hankemeier D, Manspeaker SA. Perceptions of interprofessional and collaborative practice in collegiate athletic trainers. J Athl Train. 2018;53(7):703-708. 
93. National Athletic Trainers Association. Athletic training services: an overview of skills and services performed by certified athletic trainers. National Athletic Trainers Association wed site. https://www.nata.org/sites/default/files/GuideToAthleticTrainingServices.pdf. Published January 2010. Accessed November 11, 2018.

94. McChesney JC, Peterson M. There is no off-season anymore. Athl Ther Today. 2005:10(6);610 .

95. Mazerolle SM, Pitney WA, Goodman A et al. National athletic trainers' association position statement: facilitating work-life balance in athletic training practice settings. $J$ Athl Train. 2018:53(8);796-811.

96. Pitney WA, Stuart ME, Parker J. Role strain among dual position physical educators and athletic trainers working in the high school setting. Phys Educator. 2008;65(3):157-168. 